\title{
Intracellular $A \beta$ pathology and early cognitive impairments in a transgenic rat overexpressing human amyloid precursor protein: a multidimensional study
}

\author{
M Florencia Iulita ${ }^{1 \dagger}$, Simon Allard ${ }^{1 \dagger}$, Luise Richter ${ }^{1}$, Lisa-Marie Munter ${ }^{1}$, Adriana Ducatenzeiler $^{1}$, Christoph Weise ${ }^{4}$, \\ Sonia Do Carmo', William L Klein ${ }^{5}$, Gerhard Multhaup ${ }^{1}$ and A Claudio Cuello ${ }^{1,2,3^{*}}$
}

\begin{abstract}
Numerous studies have implicated the abnormal accumulation of intraneuronal amyloid- $\beta(A \beta)$ as an important contributor to Alzheimer's disease (AD) pathology, capable of triggering neuroinflammation, tau hyperphosphorylation and cognitive deficits. However, the occurrence and pathological relevance of intracellular $A \beta$ remain a matter of controversial debate. In this study, we have used a multidimensional approach including high-magnification and super-resolution microscopy, cerebro-spinal fluid (CSF) mass spectrometry analysis and ELISA to investigate the A $\beta$ pathology and its associated cognitive impairments, in a novel transgenic rat model overexpressing human APP. Our microscopy studies with quantitative co-localization analysis revealed the presence of intraneuronal A $\beta$ in transgenic rats, with an immunological signal that was clearly distinguished from that of the amyloid precursor protein (APP) and its C-terminal fragments (CTFs). The early intraneuronal pathology was accompanied by a significant elevation of soluble $A \beta_{42}$ peptides that paralleled the presence and progression of early cognitive deficits, several months prior to amyloid plaque deposition. $A \beta_{38}, A \beta_{39}, A \beta_{40}$ and $A \beta_{42}$ peptides were detected in the rat CSF by MALDI-MS analysis even at the plaque-free stages; suggesting that a combination of intracellular and soluble extracellular $A \beta$ may be responsible for impairing cognition at early time points. Taken together, our results demonstrate that the intraneuronal development of AD-like amyloid pathology includes a mixture of molecular species (A $\beta$, APP and CTFs) of which a considerable component is $A \beta$; and that the early presence of these species within neurons has deleterious effects in the CNS, even before the development of full-blown AD-like pathology.
\end{abstract}

Keywords: Amyloid- $\beta$, APP, Intracellular A $\beta$, Pre-clinical, Alzheimer's disease

\section{Introduction}

Alzheimer's disease (AD) remains the most common form of age-related dementia, a disorder which affects approximately 36 million sufferers worldwide [1]. Recent studies have revealed the existence of a long asymptomatic phase, where the pathological changes leading to $\mathrm{AD}$ begin -at least- decades before the first symptoms of cognitive decline appear [2-4].

\footnotetext{
* Correspondence: claudio.cuello@mcgill.ca

${ }^{\dagger}$ Equal contributors

'Department of Pharmacology and Therapeutics, McGill University, 3655 Sir-William-Osler Promenade, Room 1210, Montreal, Quebec, Canada ${ }^{2}$ Department of Anatomy and Cell Biology, McGill University, Montreal, Canada

Full list of author information is available at the end of the article
}

Although these studies have addressed the temporal order in which $\mathrm{AD}$ pathological hallmarks appear, the exact sequence of cellular and molecular events that lead to $\mathrm{AD}$ is still poorly understood. However, it is widely accepted that before the overt deposition of amyloid plaques and neurofibrillary tangles, the accumulation of amyloid- $\beta(A \beta)$ peptides is one of the first steps in the series of pathogenic changes that lead to neurodegeneration and dementia $[5,6]$.

The concept of a pre-clinical, asymptomatic phase of $\mathrm{AD}$ is gaining increasing support. This is best evidenced by the recent revision of research diagnostic criteria, which now include a new detailed framework for the diagnosis and pre-clinical staging of individuals at-risk [7]. Notably, little is known about this early phase, as most studies of the $\mathrm{AD}$ 
pathology center on moderate-to-late stages. This preclinical period deserves further attention, as it should offer a critical window for successful treatment.

Given the lack of definitive AD biomarkers in humans, transgenic animal models of the amyloid pathology continue to be valuable tools to examine molecular changes preceding the deposition of amyloid plaques and associated pathology (i.e. late inflammation, neuritic dystrophy, etc.). For instance, many studies in transgenic models have demonstrated that $\mathrm{A} \beta$ accumulates first intraneuronally, before amyloid plaques appear [8-13]; a finding that has been validated in postmortem AD and Down syndrome (DS) brains [14-20].

A deeper understanding of the pre-plaque stage is of great relevance in view of the fact that the intraneuronal compartment is also a place where $A \beta$ can oligomerize $[10,21,22]$ forming toxic aggregates which can impair synaptic plasticity [23-26], induce cognitive impairments $[27,28]$ and unleash a pro-inflammatory reaction $[10,29]$. In fact, the nature and pathological relevance of the intracellularly accumulated material have been questioned in a recent study [30], raising the intriguing possibility that such material is APP, rather than A $\beta$. The arguments regarding this controversy have been recently reviewed [31]. The idea that the intraneuronal material is only APP is a challenging proposition, and we therefore considered that this issue deserved a thorough, multidisciplinary analysis.

For such study, we have used the McGill-R-Thy1-APP transgenic rat, which is unique compared to other rodent models in that the AD-like phenotype has been achieved with a single genomic insertion of a mutated human APP transgene; minimizing off-target genetic corruption and therefore being closer to the human disease [32]. Our microscopy studies at high magnification and high resolution have revealed a clear segregation between $\mathrm{A} \beta$-immunoreactivity and that of APP and its C-terminal fragments (CTFs). Soluble $A \beta_{40}$ and $A \beta_{42}$ peptides were observed elevated early, in cortex and hippocampus from transgenic rats. The increase in $A \beta$ peptides paralleled the manifestation of cognitive deficits, several months prior to amyloid plaque deposition. Notably, $A \beta_{38}, A \beta_{39}, A \beta_{40}$ and $A \beta_{42}$ peptides could be detected in the rat cerebro-spinal fluid (CSF) by MALDI-MS analysis, even at plaque-free stages. Taken together, these results indicate that the early, intracellular accumulation of soluble $\mathrm{A} \beta$ in McGill transgenic rats is already accompanied by a CNS compromise (i.e. learning and memory impairments). Further to it, we have demonstrated that the early CNS amyloid pathology is reflected and can be monitored in the rat CSF.

\section{Materials and methods \\ Animals}

Transgenic rats belonged to the McGill-R-Thy1-APP line, harboring the human APP751 transgene with the
Swedish and Indiana mutations under the control of the murine Thy1.2 promoter [11]. The 3-month old group consisted of: transgenic heterozygote $(n=7)$ and homozygote $(n=7)$ rats and non-transgenic $(n=10)$ littermates. The 7-month old group consisted of: transgenic homozygote $(n=4)$ and non-transgenic $(n=4)$ littermates. The 13-month old group consisted of: transgenic heterozygote $(n=10)$ and homozygote $(n=6)$ rats and non-transgenic $(n=10)$ Wistar rats (Charles River, Wilmington, MA), housed in identical conditions. Each group had equal gender representation. Animals were maintained on a 12hour light/12-hour dark cycle and had ad libitum access to water and a standard rodent diet. All procedures were approved beforehand by the Animal Care Committee of McGill University, following the guidelines of the Canadian Council on Animal Care.

\section{Tissue and CSF collection}

Rats were deeply anesthetized with equithesin, and CSF $(\sim 80-150 \mu \mathrm{l})$ was collected from the cisterna magna using a glass capillary and subsequently frozen at $-80^{\circ} \mathrm{C}$, following an established protocol [33]. Only clear, bloodfree CSF was used for analysis.

For tissue collection, the animals were perfused transcardially with cold saline for $1 \mathrm{~min}$. The brain was removed, one hemisphere was kept for immunohistochemistry (IHC) and the other was dissected, flash-frozen and kept at $-80^{\circ} \mathrm{C}$ for further neurochemical analysis. The hemisphere for IHC was immersion-fixed in cold $4 \%$ paraformaldehyde in $0.1 \mathrm{M}$ phosphate buffer (PB) for $24 \mathrm{~h}$ and transferred to $30 \%$ sucrose in 0.1 M PB. After the brains equilibrated in sucrose, they were cut into $40 \mu \mathrm{m}$ coronal sections with a freezing microtome (Leica SM 2000R, Germany). Brain sections were stored in cryoprotectant solution $(37.5 \% \mathrm{v} / \mathrm{v}$ ethylene glycol, $37.5 \% \mathrm{w} / \mathrm{w}$ sucrose, in $\mathrm{PBS} \mathrm{pH} 7.4$ ) at $-20^{\circ} \mathrm{C}$ until processed for IHC.

\section{Antibodies}

A detailed description of the primary antibodies used in this study can be found in Table 1 .

\section{Bright-field immunohistochemistry}

Free-floating immunostaining was done following wellestablished protocols $[10,11,34,35]$. Sections were incubated in $0.3 \%$ hydrogen peroxide in PBS for $20 \mathrm{~min}$, washed in PBS-T (0.01 M phosphate-buffered saline, $0.2 \%$ Triton $\mathrm{X}-100)$ and blocked $1 \mathrm{~h}$ with $10 \%$ normal goat serum (NGS) in PBS-T. To examine the evolution of the AD-like amyloid pathology we incubated sections with the monoclonal antibody McSA1 [36] (MediMabs, Montreal, Canada) at 1:4000 in PBS-T with 5\% NGS overnight at $4^{\circ} \mathrm{C}$. The following day, the sections were washed in PBS-T and incubated with a goat anti-mouse secondary antibody (MP Biochemicals, Canada) 1:100 in 
Table 1 List of antibodies used in this study

\begin{tabular}{ccccc}
\hline Antibody name & Antibody target & Source & Epitope recognized & Obtained from \\
\hline McSA1 & Human $A \beta$ & Mouse monoclonal & N-terminus of human A $\beta$ (residues 1-12) & Medimabs, Canada \\
MOAB-2 & Human A & Mouse monoclonal & N-terminus of human A $\beta$ (residues 1-4) & Biosensis, Australia \\
Nu1 & Human A oligomers & Mouse monoclonal & Conformational, A $\beta$ oligomers & Dr. William Klein, Northwestern University \\
pab27576 & APP & Rabbit polyclonal & Last 43 C-terminal residues of APP & Dr. Gerhard Multhaup, McGill University \\
W0-2 & Human A & Mouse monoclonal & N-terminus of human A $($ residues 4-10) & EMI Millipore, USA \\
G2-10 & Human $A \beta_{40}$ & Mouse monoclonal & C-terminus of A $\beta_{40}$ & EMI Millipore, USA \\
G2-13 & Human $A \beta_{42}$ & Mouse monoclonal & C-terminus of A $\beta_{42}$ & EMI Millipore, USA \\
\hline
\end{tabular}

PBS with 5\% NGS for $1 \mathrm{~h}$. The sections were washed in PBS and incubated for $1 \mathrm{~h}$ with a mouse anti-peroxidase monoclonal antibody [37] (1:30) pre-incubated with horseradish peroxidase $(5 \mu \mathrm{g} / \mathrm{ml})$ in PBS (MAP kit, Medimabs, Canada). Stainings were developed with $0.06 \% 3,3^{\prime}$-diaminobenzidine (Sigma-Aldrich, USA) and 0.01\% hydrogen peroxide (Sigma-Aldrich, USA) in PBS and then mounted on subbed slides. Sections were dehydrated in increasing ethanol concentrations (70-100\%) and xylene, prior to coverslipping with Entellan (EM Science, USA). Images were acquired on an Axioplan Imaging microscope equipped with an AxioCam HRc digital camera (Carl Zeiss, Toronto, Canada); using the Axiovision 4.8 Software.

\section{Immunofluorescence and confocal microscopy}

Immunofluorescence was done following established protocols $[10,38]$. Sections were incubated in 50\% ethanol for 20 min followed by three 10-min washes in PBS. Blocking was done in $10 \%$ NGS in PBS-T during $1 \mathrm{~h}$. Primary antibodies were incubated overnight in 5\% NGS at $4^{\circ} \mathrm{C}$. Double labeling was performed between three anti-A $\beta$ antibodies (McSA1, Medimabs, Canada; MOAB-2 [39], Biosensis, Australia and Nu1 [40], provided by Dr. William Klein, Northwestern University, USA; at 1:500) and a polyclonal antibody (pab27576, provided by Dr. Gerhard Multhaup, McGill University; at 1:500) directed against the last 43 amino acids of the $\mathrm{C}$-terminal domain of APP. This antibody recognizes full-length APP $(\sim 100 \mathrm{kDa})$ and CTFs $(\sim 12 \mathrm{kDa})$ without crossreactivity for $A \beta[13,41,42]$. Alexa 488-conjugated goat anti-mouse (Jackson Immunoresearch, USA) and Alexa 594-conjugated goat anti-rabbit (Molecular Probes, USA) secondary antibodies were applied overnight at 1:400-1:800 in PBS with 5\% NGS. Sections were washed three times in PBS and subsequently mounted on gelatin subbed slides, dried overnight at $4^{\circ} \mathrm{C}$, and coverslipped with Aqua Polymount (Polysciences, USA).

Images were taken on a Zeiss LSM 510 confocal microscope (Carl Zeiss, Canada) equipped with Argon and Helium-Neon lasers. Three sections per animal were immunolabeled and five pictures per animal (per region) were acquired from area CA1 of the hippocampus and lamina V and III of the parietal cortex. To maximize the sensitivity of co-localization analysis and fully exploit the resolution of the microscope objective (Zeiss $63 \mathrm{X}$ oil immersion objective NA =1.4), we used a 3.0 scan zoom so that each pixel covered $0.05 \mu \mathrm{m}$. Each signal was acquired using separate tracts with the appropriate laserfilter settings to avoid bleed-through of signals, and the pinhole was set so that optical sections were less than $0.7 \mu \mathrm{m}$ thick. With the given objective settings, the theoretical resolution was of $250 \mathrm{~nm}$ in $x, y$ and $700 \mathrm{~nm}$ in the $z$ plane.

Confocal images were analyzed and quantified with the JACoP plugin [43] of the Image J software, to obtain Pearson and Manders' correlation coefficients. The Pearson coefficient defines the quality of the linear relationship between two signals and varies between 1 and -1 . Manders' coefficients (M1 and M2) indicate the proportion of signal overlap; varying from 0 (no co-localization) to 1 (perfect co-localization). In this study, M1 indicated the proportion of McSA1 (or MOAB-2 or Nu1) (green signal) overlapping pab27576 immunoreactivity (red signal) over its total intensity. Conversely, M2 is defined as the proportion of pab27576 signal (red) overlapping McSA1/MOAB-2/Nu1 immunolabels (green) over its total intensity. Omission of primary antibodies resulted in no detectable fluorescent staining (data not shown).

\section{Structured Illumination Microscopy (SIM)}

Given that both McSA1 and pab27576 gave robust fluorescent signals, we were able to image them by SIM a super-resolution microscopy technique permitting a resolution of $\sim 100 \mathrm{~nm}$ in $x, y$ and of $\sim 300 \mathrm{~nm}$ in $z$ [44]. The IHC was done following the same protocol as for the confocal experiments, except that the McSA1 and pab27576 were used at a concentration of 1:1000. Images were taken on a DeltaVision OMX V4 Blaze superresolution microscope (Applied Precision, GE Healthcare). Reconstructed images were visualized using the Volocity 3D Image Analysis Software (PerkinElmer, USA). Following image reconstruction and registration, serial $z$ planes were assembled to form a 3D model using the Volocity Software. A video showing different rotations and magnifications of 
the 3D model was made using the video tools from the software (Additional file 1: Video).

\section{Human $A \beta_{40}$ and $A \beta_{42}$ ELISA}

Brains were homogenized in $8 \%$ vol $(\mathrm{w} / \mathrm{v})$ of cold TBS buffer (150 mM NaCl, $50 \mathrm{mM}$ Tris / $\mathrm{HCl}, 5 \mathrm{mM}$ EDTA, $\mathrm{pH}$ 7.6) containing a protease inhibitor cocktail (Roche, Germany) using a teflon-glass homogenizer. Homogenates were cleared by centrifugation at $100.000 \mathrm{~g}$ for $1 \mathrm{~h}$ at $4^{\circ} \mathrm{C}$, and supernatants were collected for further analysis (TBSsoluble fraction). The remaining pellets were dissolved in $70 \%$ formic acid (FA) with $50 \%$ of homogenization volume and sonicated for $30 \mathrm{~s}$ at $30 \%$ power. Centrifugation at $100.000 \mathrm{~g}$ was repeated and supernatants were collected (FA-soluble fraction). Samples from FA-soluble fractions were neutralized with $1 \mathrm{M}$ Tris, $0.5 \mathrm{M} \mathrm{Na}_{2} \mathrm{HPO}_{4}$ prior to ELISA analysis.

Levels of $A \beta_{40}$ or $A \beta_{42}$ in TBS-soluble and FA-soluble fractions were determined by sandwich ELISA. The Cterminus-specific anti-A $\beta$ monoclonal antibodies $\mathrm{G} 2-10$ and G2-13 (EMI Millipore, USA) were used to capture A $\beta$ species terminating at 40 or 42 amino acids, respectively. The monoclonal biotinylated W0-2 (EMI Millipore, USA) recognizing the $\mathrm{A} \beta \mathrm{N}$-terminus was used as detection antibody, and the reaction was developed by streptavidinhorseradish peroxidase conjugate and the chromogenic substrate 1-Step Ultra-TMB (Pierce, USA). After stopping the reaction with $1 \mathrm{M} \mathrm{H}_{2} \mathrm{SO}_{4}$, the enzymatic products were measured at $450 \mathrm{~nm}$ in a microplate reader (Anthos HT2, Germany). Synthetic $A \beta_{40}$ or $A \beta_{42}$ peptides (EMI Millipore, USA) served as standards.

\section{MALDI-MS analysis of $A \beta$ peptides in rat CSF}

$\mathrm{A} \beta$ was immunoprecipitated from $50 \mu \mathrm{l}$ CSF with $5 \mu \mathrm{g}$ of the anti-A $\beta$ antibody W0-2 (EMI Millipore, USA) coupled to protein-G sepharose beads (GE Healthcare, USA) and incubated overnight at $4^{\circ} \mathrm{C}$. The beads were washed three times with PBS and twice with $50 \mathrm{mM}$ ammonium acetate, $\mathrm{pH}$ 7.0. A $\beta$ was eluted twice with $50 \%$ acetic acid and vacuum-dried overnight. Immunoprecipitated samples were resuspended in $10 \mu \mathrm{l}$ of TA (33\% acetonitrile, $0.1 \%$ trifluoroacetic acid) and sonicated in a water bath for $10 \mathrm{~min}$. Samples were spotted by the dried droplet technique mixing $1 \mu \mathrm{l}$ of sample with $1 \mu \mathrm{l}$ of a TA solution saturated with sinapinic acid. MALDIMS analysis was carried out on a Bruker Ultraflex II instrument (Bruker Daltonik, Bremen, Germany).

\section{Behavioral studies}

Tests were conducted during the light phase of the circadian cycle. Rats were handled prior to testing for 2-3 days. Experimenters were blinded to the genotype during all behavioral studies.

\section{Fear conditioning}

The fear conditioning protocol was designed adapting a previously reported procedure [45]. Animals were tested in a single chamber connected to a weight transducer system to allow the tracking of movement (Panlab, Spain). The chamber was scented with coconut extract and cleaned with ethanol $70 \%$ between animals. To create a different environment for the fear memory retention test, the walls of the chamber were decorated with visual cues; the chamber was scented with mint extract and cleaned with acetic acid $1 \%$ between animals.

On day 1 (habituation) rats were allowed to explore the chamber for $5 \mathrm{~min}$ and returned to their home cages. On day 2 (conditioning), after an initial $90 \mathrm{sec}$ phase of exploration (baseline), a $30 \mathrm{sec}$ tone (75 dB, $5 \mathrm{kHz}$ ) was presented which co-terminated with a $2 \mathrm{sec}$ foot shock $(0.75 \mathrm{~mA})$. Animals were allowed to recover (post-shock; $120 \mathrm{sec}$ ) and returned to their home cages. On day 3, contextual fear conditioning was evaluated by placing the animals in the chamber during $8 \mathrm{~min}$. On day 4, animals were allowed to explore the "new" arena for $120 \mathrm{sec}$ (baseline). This was followed by three consecutive tone presentations (30 sec, $75 \mathrm{~dB}, 5 \mathrm{kHz}$ ), each separated by a $30 \mathrm{sec}$ pause. The Freezing software (Freezing v1.3.01, Panlab) recorded all freezing episodes in each of the test phases, considering freezing as immobility for at least 2 sec.

\section{Novel object recognition and location}

Before testing, the animals were habituated to the testing environment by allowing them to explore the experimental arena. Following habituation, the rats were subjected to three testing phases: Exploration, Novel Object Location (NOL) and Novel Object Recognition (NOR). During exploration, five objects similar in size but different in color, shape and texture were put in the arena. These objects have been tested in pilot studies to ensure that none of them elicited spontaneous preference or avoidance. The animals were allowed to explore the objects for three sessions of $2 \mathrm{~min}$, with a $10 \mathrm{~min}$ intersession interval. An animal was considered as exploring when the muzzle was touching or in close proximity to the objects. The NOL test consisted of a single $2 \mathrm{~min}$ session where one of the objects was moved to a new location. For NOR, one of the undisplaced objects was substituted by a novel one. For NOL and NOR, the time exploring familiar and displaced/novel objects was recorded separately to calculate the discrimination ratio. We defined this ratio as the difference in exploration time for the displaced or novel object divided by total exploration time. Increased time spent exploring the object in the novel location was interpreted as successful spatial memory. Increased time spent exploring the novel 
object was interpreted as successful recognition memory for the familiar objects versus the novel one.

\section{Calculation of cognitive index}

For correlation analysis between behavior and $A \beta$ pathology, a global learning and memory score, referred as cognitive index, was calculated based on the animals' performance during each different phase of behavior tests. For auditory and cue fear conditioning, a score was computed by calculating the fold increase in freezing behavior during the post-shock phase and tone presentation (respectively), compared to baseline freezing. Context conditioning freezing percentages were converted to a 10-point scale. For NOL and NOR, a score was obtained by calculating the fold increase between the animal's discrimination ratio and that of chance levels. All behavior scores were added and expressed as a $z$ score, referred here as "cognitive index".

\section{Von Frey test}

Animals were habituated to the testing environment by placing them in individual boxes on a metal mesh floor during $10 \mathrm{~min}$. The following day mechanical sensitivity was assessed by measuring withdrawal responses to a series of calibrated Von Frey filaments with incrementing force (15 g, $26 \mathrm{~g}, 60 \mathrm{~g}$ and $100 \mathrm{~g})$. These were applied perpendicularly to the plantar surface of both hind paws, following the "up and down" method [46]. Each hind paw was poked twice, calculating an average of all four pokes for between-animal comparisons.

\section{Statistical analysis}

The software Graph Pad Prism 5.01 (La Jolla, CA, USA) was used for statistical analysis. One-way ANOVA was used for three-group comparisons, followed by post-hoc multiple comparison tests (as specified in figure legend). Two-way ANOVA was used to analyze the fear conditioning data. Graphs illustrate mean \pm SEM.

\section{Results \\ Progression of the amyloid pathology in \\ McGill-R-Thy1-APP transgenic rats}

This study provides a quantitative biochemical and morphological investigation of the evolution of the $A \beta$ pathology and its associated cognitive impairments in McGill-R-Thy1-APP rats. In this rat model, the expression of A $\beta$-immunoreactive material is detectable as early as 1 week of age and the first isolated amyloid plaques may appear between $6-8$ months starting in the subiculum [11].

We defined the pre-plaque stage of the amyloid pathology as a stage where $A \beta$ immunoreactivity is limited to the intraneuronal compartment in the absence of extracellular amyloid plaques, as detected with the anti-A $\beta$
McSA1 monoclonal antibody (Figure 1). In this cohort, 3 and 7 month-old McGill transgenic rats displayed robust intracellular McSA1 immunoreactivity and no evidence of amyloid plaque deposition (Figure 1). By 13 months, homozygote $(+/+)$ animals displayed widespread and abundant amyloid plaques throughout the cortex (with greatest expression in lamina V) (Figure 1c, i), hippocampus (Figure 1 c, f) and amygdala (Figure 1l). Heterozygote transgenic rats of comparable age (13 months) did not exhibit amyloid plaques (Figure 1n, o). In this rat model, the amyloid pathology at advanced stages (18-20 months) is further accompanied by strong microglial activation and dystrophic neuries surrounding amyloid plaques [11]. Absence of McSA1-immunoreactivity was observed in non-transgenic animals (Figure $1 \mathrm{~m}$ ), at all time points examined.

\section{Quantitative co-localization analysis between $A \beta$ and APP/CTF-specific signals}

To detect intracellular $A \beta$ we utilized the monoclonal antibody (McSA1), which recognizes the N-terminal region of the human $A \beta$ peptide (residues 1-12) [36]. This epitope could theoretically be found as well in $\beta$-CTF and in the APP molecule. However, competition studies have demonstrated that the McSA1 antibody is highly specific for A $\beta$ as opposed to APP or sAPP- $\alpha[11,36]$.

We performed quantitative co-localization analysis between McSA1 and pab27576 immunoreactivities with the JACoP/Image J software (Figure 2a), at pre- and postplaque stages of the amyloid pathology. At 3 months of age (pre-plaque stage) we observed only a partial colocalization between McSA1 and pab27576 immunoreactivity in neurons from lamina $\mathrm{V}$ (Figure $2 \mathrm{~b}$ ), as reflected by an average Pearson coefficient of $0.44 \pm 0.03$ (Table 2). Quantitative analysis demonstrated only $~ 30 \%$ overlap $(\mathrm{M} 1=0.30 \pm 0.03)$ between McSA1 and pab27576 signals in lamina $\mathrm{V}$ neurons (Table 2), indicating that $\sim 70 \%$ of the cellular epitope recognized by McSA1 is not coming from APP or $\beta$-CTFs. Similar observations were made in CA1 neurons and in neurons from lamina III of the cortex (Additional file 2: Figure S1), revealing Pearson coefficients of $0.57 \pm 0.02$ and $0.32 \pm 0.03$ and a degree of overlap of only $\sim 20-50 \%$ between the two signals ( $\mathrm{M} 1=$ $0.48 \pm 0.02$ and $\mathrm{M} 1=0.23 \pm 0.03$; respectively) (Table 2). The clear distinction between intracellular McSA1 and pab27576 immunoreactivities was also evident at later stages of the amyloid pathology (Additional file 2: Figure S1). Pearson coefficients ranged between 0.35 and 0.5 and there was approximately $\sim 20-40 \%$ overlap between the two signals in the brain regions investigated (Table 2). At this time point, we also observed the presence of extracellular amyloid deposits that were McSA1 positive but pab27576 negative (Additional file 3: Figure S2c).

Strikingly, the intracellular McSA1 immunolabeling appeared diffusely distributed throughout the neuronal 

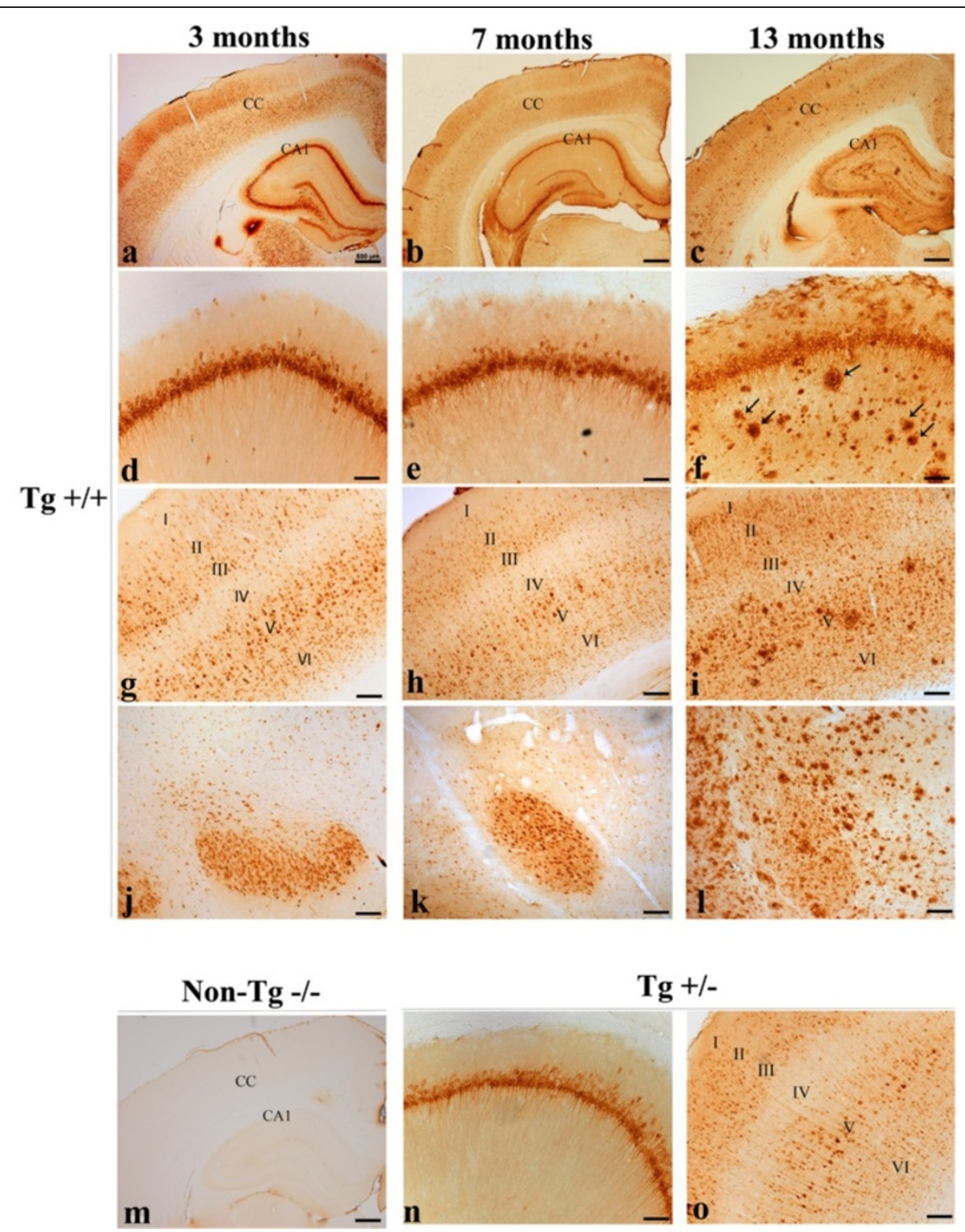

Figure 1 Temporal progression of the AD-like amyloid pathology in McGill-R-Thy1-APP transgenic rats. Intense intraneuronal AB immunoreactivity is observed in McGill transgenic rats throughout the neocortex (a-c, $\mathbf{g}-\mathbf{i} \mathbf{i} \mathbf{o})$, hippocampus (a-f, $\mathbf{n}$ ) and amygdala (j-I), as detected with the anti-AB MCSA1 monoclonal antibody. Note the absence of amyloid plaques at 3 months and 7 months of age. At 13 months, transgenic rats exhibited strong intracellular and extracellular McSA1 immunoreactivity. Abundant amyloid plaque deposition is evident throughout all cortical layers, hippocampal formation and amygdala in homozygote transgenic rats. Arrows indicate the presence of amyloid plaques. MCSA1 immunoreactivity remained limited to the intracellular compartment in heterozygote animals. Note the absence of McSA1-immunoreactivity in non-transgenic animals (m). Scale bar: a-c, $m=500 \mu m ; d-l, n-0=100 \mu m$.

cytoplasm, whereas the pab27576 signal was mostly associated to vesicular-like structures within the perinuclear region (Figure 2 and Additional file 2: Figure S1). To obtain a higher, optimal 3D resolution of McSA1 and pab27576 immunoreactivities at the pre-plaque stage, we applied super-resolution SIM microscopy. With this technique, we finally demonstrate that the overlap between McSA1 and pab27576 immunoreactive sites was minimal, where the former diffuse McSA1 signal now became localized to small intracellular vesicles, clearly dissociated from pab27576 immunoreactive structures (Figure 3). For a better illustration of the dissociation between $A \beta$ and APP/CTF-specific signals, a 3D model was generated following image reconstruction and registration and assembly of serial $z$ planes (Additional file 1: Video).

To further validate our inclusion/exclusion co-localization analysis we then stained rat brain sections with MAOB-2, a monoclonal antibody directed to residues $1-4$ of $A \beta$, and 


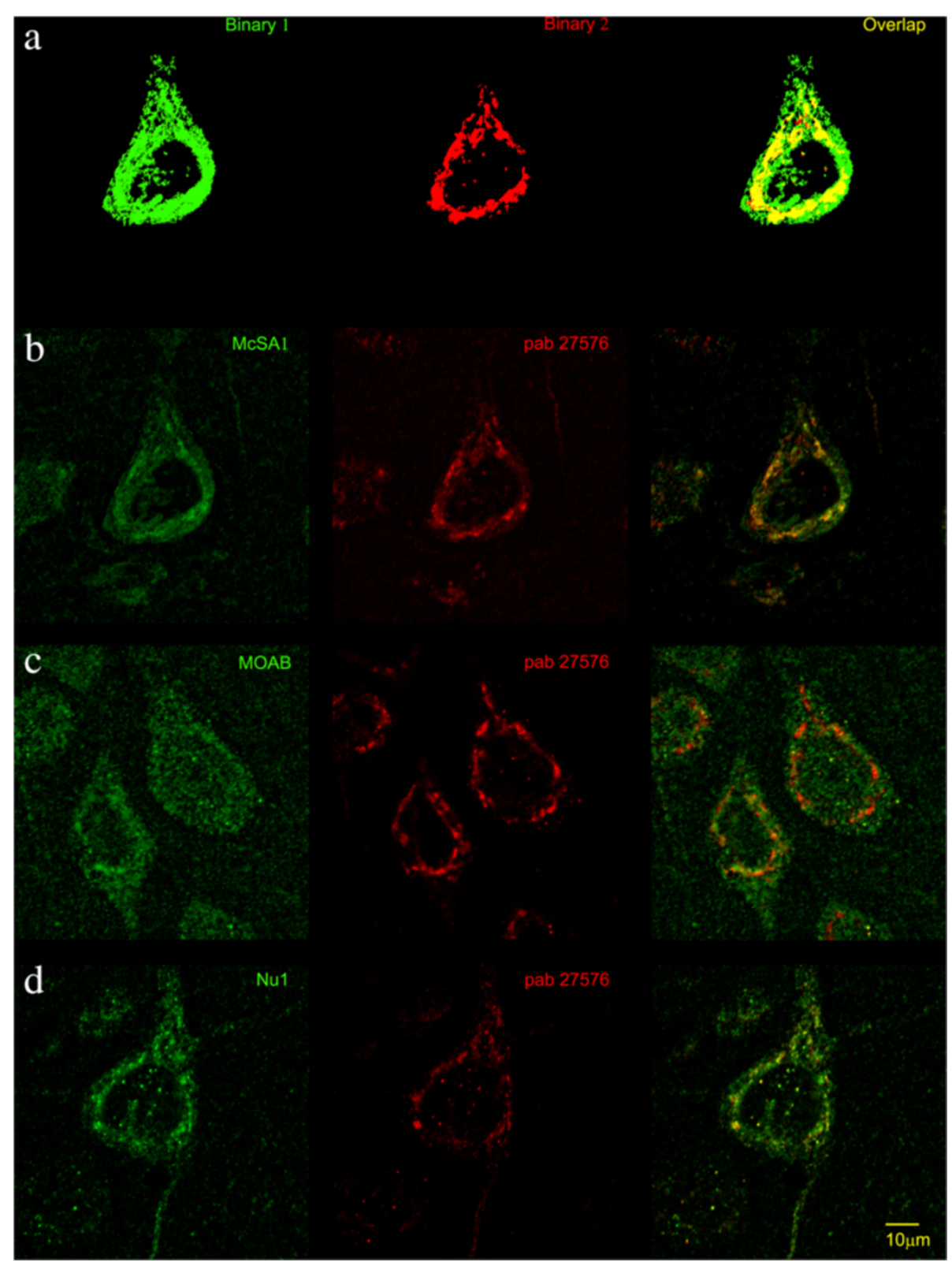

Figure 2 Detection of intraneuronal $\mathbf{A} \boldsymbol{\beta}$ and APP/CTFs. a) To measure the overlap coefficient of different antibody binding sites, the signals were separated from background using a brightness criterion and made binary. The two images were then superimposed; the M1 coefficient represents the overlap (yellow) divided by the total green signal (yellow + green). The M2 coefficient represents the overlap divided by the total red signal (yellow + red). b-d) Representative high-magnification confocal micrographs depicting co-localization between pab27576 (red) and b) McSA1 (green) binding sites, c) MOAB-2 (green) and d) Nu1 (green) in lamina $V$ neurons of the parietal cortex, at the pre-plaque stage (3 month-old transgenic rats). Note the lack of complete overlap between A 3 - and APP/CTF-specific signals. Scale bar $=10 \mu \mathrm{m}$.

which has been reported as absent of cross-reactivity with APP or CTFs [39]. In general, the MOAB-2 immunoreaction ranged from low (in some neurons) to hardly detectable in most neurons from the different areas and time points examined. Therefore, we subjected confocal images to quantitative co-localization analysis only when the MOAB-2 signal was strong enough to be clearly distinguished from background, non-specific staining. Corroborating our previous results with McSA1, we observed a differential pattern of immunoreactivity between MOAB-2 and pab27576 in cells with detectable and reliable MOAB-2 staining. At 3 months of age (pre-plaque) high-magnification quantitative co-localization analysis revealed only a partial overlap between the two signals in neurons from lamina $\mathrm{V}$ (Figure 2c), as reflected by an average Pearson coefficient of $0.41 \pm 0.01$ and M1 coefficient of $0.44 \pm 0.02$. At 
Table 2 Co-localization analysis between McSA1 and pab27576

\begin{tabular}{ccccc}
\hline & & Pearson & Manders M1 & Manders M2 \\
\hline \multirow{3}{*}{3 months } & CA1 & $0.57 \pm 0.02$ & $0.48 \pm 0.02$ & $0.83 \pm 0.02$ \\
& Lamina V & $0.44 \pm 0.03$ & $0.30 \pm 0.03$ & $0.65 \pm 0.04$ \\
& Lamina III & $0.32 \pm 0.03$ & $0.23 \pm 0.03$ & $0.56 \pm 0.04$ \\
\multirow{3}{*}{13 months } & CA1 & $0.51 \pm 0.04$ & $0.37 \pm 0.02$ & $0.79 \pm 0.03$ \\
& Lamina V & $0.39 \pm 0.03$ & $0.22 \pm 0.02$ & $0.74 \pm 0.03$ \\
& Lamina III & $0.35 \pm 0.03$ & $0.22 \pm 0.02$ & $0.64 \pm 0.04$
\end{tabular}

M1: proportion of McSA1-IR (green) overlapping pab27576 (red) over its total intensity.

M2: proportion of pab27576 (red) overlapping McSA1-IR (green) over its total intensity.

13 months of age, the intracellular MOAB-2 immunolabel was hardly detectable in pyramidal neurons adjacent to amyloid plaques, the latter which were strongly labeled by this antibody and not by pab27576 (Additional file 3: Figure S2 a-b).

Additional confirmation of the segregation between $\mathrm{A} \beta$-specific and APP/CTF-specific signals was obtained by co-labeling transgenic rat brain sections with the $\mathrm{Nu} 1$ monoclonal antibody (conformational, $A \beta$ oligomer-specific) [40] and pab27576. With this approach, a similar clear distinction between A $\beta$-specific and APP/CTF-specific intraneuronal signals was observed. At the pre-plaque stage (3 months) we revealed only a partial co-localization between Nu1 and pab27576 immunoreactivity in neurons from lamina V (Figure 2d), indicated by an average Pearson coefficient of $0.53 \pm 0.02$ (Table 3). Quantitative analysis also demonstrated only $\sim 40 \%$ overlap (M1 $=0.37 \pm$ 0.02) between Nu1 and pab27576 signals in lamina V pyramidal neurons (Table 3). Similar observations were made in CA1 and lamina III (Additional file 4: Figure S3), revealing Pearson coefficients of $0.64 \pm 0.01$ and $0.35 \pm 0.02$ and a degree of overlap of $\sim 25-50 \%$ between the two signals $(\mathrm{M} 1=0.50 \pm 0.02$ and $\mathrm{M} 1=0.24 \pm 0.02$; respectively) (Table 3). At 13 months of age co-localization analysis further revealed a clear distinction between intracellular Nu1 and pab27576 immunoreactivity (Additional file 4: Figure S3). Pearson coefficients ranged between $0.4-0.7$ throughout the three brain regions and there was approximately $40-50 \%$ overlap between the signals (Table 3). At both stages of the amyloid pathology, the intracellular Nu1 immunolabel appeared associated to vesicle-like structures.

\section{Analysis of $A \beta$ peptides in brain}

We further quantified the age-dependent accumulation of $\mathrm{A} \beta$ peptides in McGill transgenic rat brain homogenates by ELISA following established protocols $[47,48]$. We observed significantly higher levels of soluble $A \beta_{40}$ peptides ( $\sim 3$ fold) in cortex and hippocampus from transgenic rats compared to age-matched non-transgenic animals, at 3 months $(\mathrm{p}<0.0001), 7$ months $(\mathrm{p}<0.001)$ and $13-15$ months of age $(p<0.01)$ (Figure $4 a)$. The levels of soluble

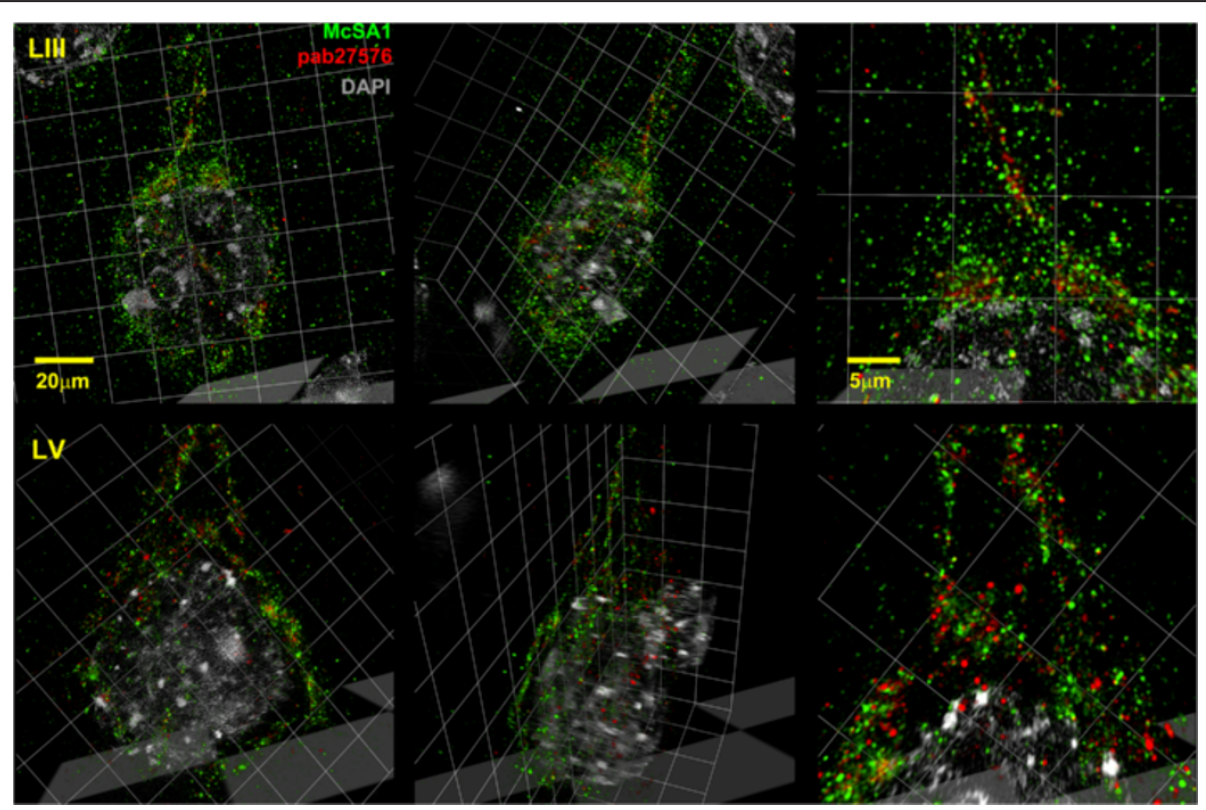

Figure 3 Characterization of McSA1 and pab27576 immunoreactivities by super-resolution microscopy. To further characterize the distribution of McSA1 and pab27576 signals, pyramidal neurons from lamina III and lamina V of the parietal cortex were imaged by SIM in 3-month old amyloid-plaque free transgenic rats. Note the distinct intracellular localization of McSA1 immunoreactivity (green) with that of pab27576 (red), denoting Aß-amyloid peptides and APP/CTFs, respectively. DAPI (gray) indicates the boundaries of the neuronal nucleus. From left to right are frontal and oblique views, followed by higher magnification images of 3D-reconstructions. 
Table 3 Co-localization analysis between Nu1 and pab27576

\begin{tabular}{ccccc}
\hline & & Pearson & Manders M1 & Manders M2 \\
\hline \multirow{3}{*}{3 months } & CA1 & $0.64 \pm 0.01$ & $0.50 \pm 0.02$ & $0.70 \pm 0.02$ \\
& Lamina V & $0.53 \pm 0.03$ & $0.37 \pm 0.02$ & $0.61 \pm 0.04$ \\
& Lamina III & $0.35 \pm 0.02$ & $0.24 \pm 0.02$ & $0.43 \pm 0.03$ \\
\multirow{3}{*}{13 months } & CA1 & $0.63 \pm 0.05$ & $0.51 \pm 0.03$ & $0.84 \pm 0.02$ \\
& Lamina V & $0.68 \pm 0.04$ & $0.49 \pm 0.03$ & $0.79 \pm 0.03$ \\
& Lamina III & $0.47 \pm 0.02$ & $0.37 \pm 0.02$ & $0.56 \pm 0.03$ \\
\hline
\end{tabular}

M1: proportion of Nu1-IR (green) overlapping pab27576 (red) over its total intensity.

M2: proportion of pab27576 (red) overlapping Nu1-IR (green) over its total intensity.

$A \beta_{40}$ peptides, however, did not differ significantly between transgenic rats at different stages of the amyloid pathology, with an average of $50.2 \pm 4.7 \mathrm{pg} / \mathrm{mg}$ total protein. Furthermore, cortical and hippocampal levels of TBS-soluble $A \beta_{42}$ peptides were slightly elevated in young McGill transgenic rats (3 and 7 months) compared to non-transgenic animals (Figure 4b), whereas substantially more $A \beta_{42}$ was found in 13-15 month-old transgenics $(171 \pm 37.8 \mathrm{pg} / \mathrm{mg}$ protein, $\mathrm{p}<0.0001)$. This data strongly suggests an age-dependent accumulation of soluble $A \beta_{42}$ peptides in McGill transgenic rats $(p<0.001)$. Notably, levels of TBS-soluble $A \beta_{40}$ and $A \beta_{42}$ were slightly increased in heterozygote $(+/-)$ rats at $13-15$ months of age compared to non-transgenic littermates, though not significantly (Figure 4a-b).

When analyzing the presence and levels of $A \beta$ in FA fractions we detected highest concentrations of $A \beta_{40}$ $(938.3 \pm 313.9 \mathrm{pg} / \mathrm{mg}$ protein, $\mathrm{p}<0.001)$ and $\mathrm{A} \beta_{42}$ $(3246.1 \pm 963.7 \mathrm{pg} / \mathrm{mg}$ protein, $\mathrm{p}<0.0001)$ in transgenic rats at $13-15$ months of age compared to plaque-free transgenic rats (Figure $4 \mathrm{c}-\mathrm{d}$ ), with an average $\mathrm{A} \beta_{42} / \mathrm{A} \beta_{40}$ ratio of $6 \pm 2$. Thus, this data revealed that $\sim 95 \%$ of the total $A \beta_{40}$ and $A \beta_{42}$ detected in the cortex and hippocampus of transgenic rat at the post-plaque stage required FA for solubilization. There was no difference or age-dependent increase in the level of TBS-soluble or FA-treated A $\beta$ peptides in cerebellum between non-transgenic and transgenic animals (Additional file 5: Figure S4); a finding that is in agreement with the human pathology [49].

\section{a}

A $\beta 40$ (TBS-soluble fraction)

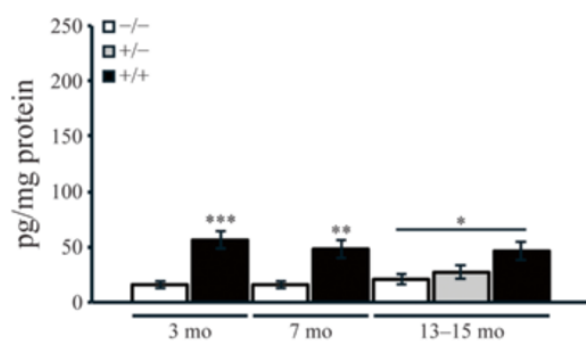

c

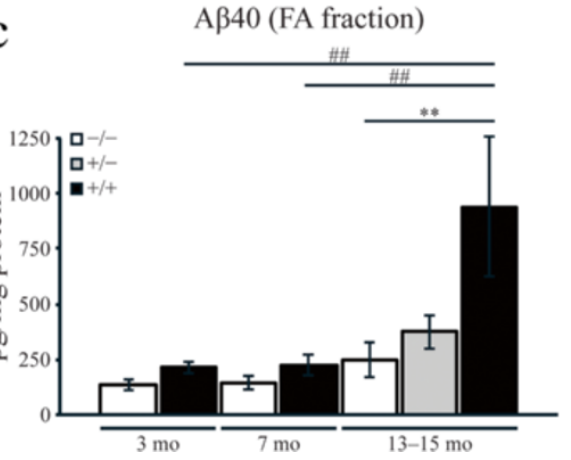

b

A 342 (TBS-soluble fraction)

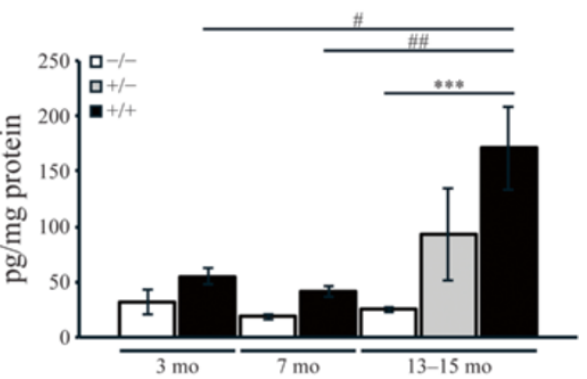

d

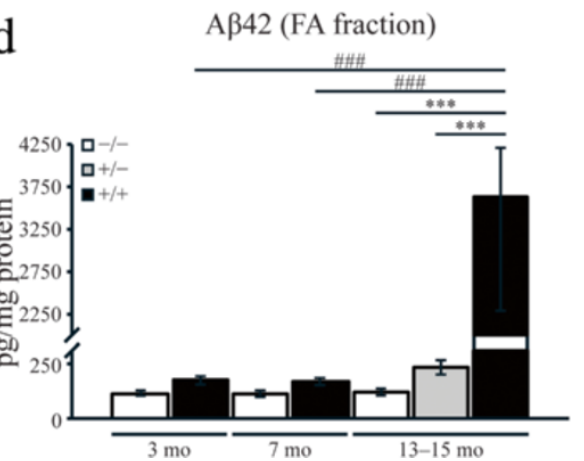

Figure 4 Quantification of $A \beta_{40}$ and $A \beta_{42}$ levels in cortex and hippocampus by sandwich ELISA. TBS-soluble a) $A \beta_{40}$ and $\left.\mathbf{b}\right) A \beta_{42}$ levels in cortex + hippocampus homogenates from non-transgenic (-/-), heterozygous $(+/-)$ and homozygous transgenic $(+/+)$ rats at different ages (3 months, 7 months and 13-15 months) were quantified with specific G2-10/W0-2 and G2-13/W0-2 sandwich ELISAs, respectively. TBS-insoluble pellets were extracted with $70 \%$ formic acid (FA) and after neutralization, c) $A \beta_{40}$ and $\mathbf{d}$ ) $A \beta_{42}$ levels in FA fractions were assayed with G2-10/ W0-2 and G2-13/W0-2 ELISAs, respectively. Values were normalized to total protein concentration and expressed as means \pm SEM. One-way ANOVA, followed by Dunnett's post-hoc test. ${ }^{*} P<0.01$, ${ }^{* *} P<0.001$, ${ }^{* *} P<0.0001$ (across the same time point), ${ }^{\#} P<0.01,{ }^{\# \#} P<0.001,{ }^{\# \# \#} P<0.0001$ (across ages). 


\section{Analysis of $A \beta$ peptides in CSF}

In order to detect $A \beta$ peptides in CSF, we immunoprecipitated human $\mathrm{A} \beta$ with the W0-2 antibody (Table 1). MALDIMS analysis revealed the presence of $A \beta_{42}(4513 \mathrm{Da}), A \beta_{40}$ (4329 Da), $A \beta_{39}(4230 \mathrm{Da})$ and $A \beta_{38}(4131 \mathrm{Da})$ peptides in CSF from McGill transgenic rats, both at pre- and postplaque stages of the amyloid pathology (Figure 5).

Notably, the pattern of CSF peptides was similar at both time points and comparable to that observed in human CSF [50]; except for two observations: no $A \beta_{37}$ was detected in the CSF of McGill transgenic rats at any time point and the $A \beta_{38}$ signal was as strong as the $A \beta_{40}$ signal, under these conditions. MALDI-MS analysis revealed an absence of $A \beta$ signal in non-transgenic animals (Figure 5) at both time points, indicating that detected $A \beta$ peptides predominantly derive from the human APP transgene expression or reflecting the low level of endogenous rodent $A \beta$ [51]. The masses identified as $A \beta$ peptides were absent when immunoprecipitation was performed from PBS instead of CSF.

Early and progressive cognitive deficits in McGill-R-Thy1-APP rats

Impaired fear conditioning

During auditory conditioning training (Figure 6a), 3 monthold transgenic and non-transgenic animals exhibited low, comparable baseline freezing behavior. The initial presentation of the tone, before the foot-shock, did not result in increased freezing behavior in any of the groups. Conversely, we observed marked differences in fear response acquisition between transgenic animals and non-transgenic littermates during the post-shock phase $\left(\mathrm{F}_{2,21}=17.03 ; \mathrm{p}<0.001\right)$.

In the fear conditioning paradigm, animals can also learn to associate the environment with the aversive stimulus; therefore, we tested contextual fear conditioning behavior $24 \mathrm{~h}$ later in the same arena, and compared it to the average freezing response during the pre-training habituation session (which averaged $\sim 10 \%$ freezing). No differences in freezing responses between non-transgenic and transgenic rats were detected during contextual fear conditioning testing at this early stage $\left(\mathrm{F}_{2,21}=1.043 ; \mathrm{p}>\right.$ 0.05 ) (Figure 6b). Following contextual fear conditioning, we then tested fear memory retrieval in response to an auditory cue, within a different environment. All rats exhibited low, comparable freezing responses at baseline. However, upon tone presentation, McGill transgenic rats manifested significant deficits in amygdala-dependent auditory fear memory, compared to non-transgenic littermates $\left(\mathrm{F}_{2,21}=47.12 ; \mathrm{p}<0.001\right)$ (Figure $6 \mathrm{c}$ ). Therefore, fear conditioning deficits were detectable at early stages of the amyloid pathology, in the absence of amyloid plaques. At this early time-point, transgenic homozygotes and

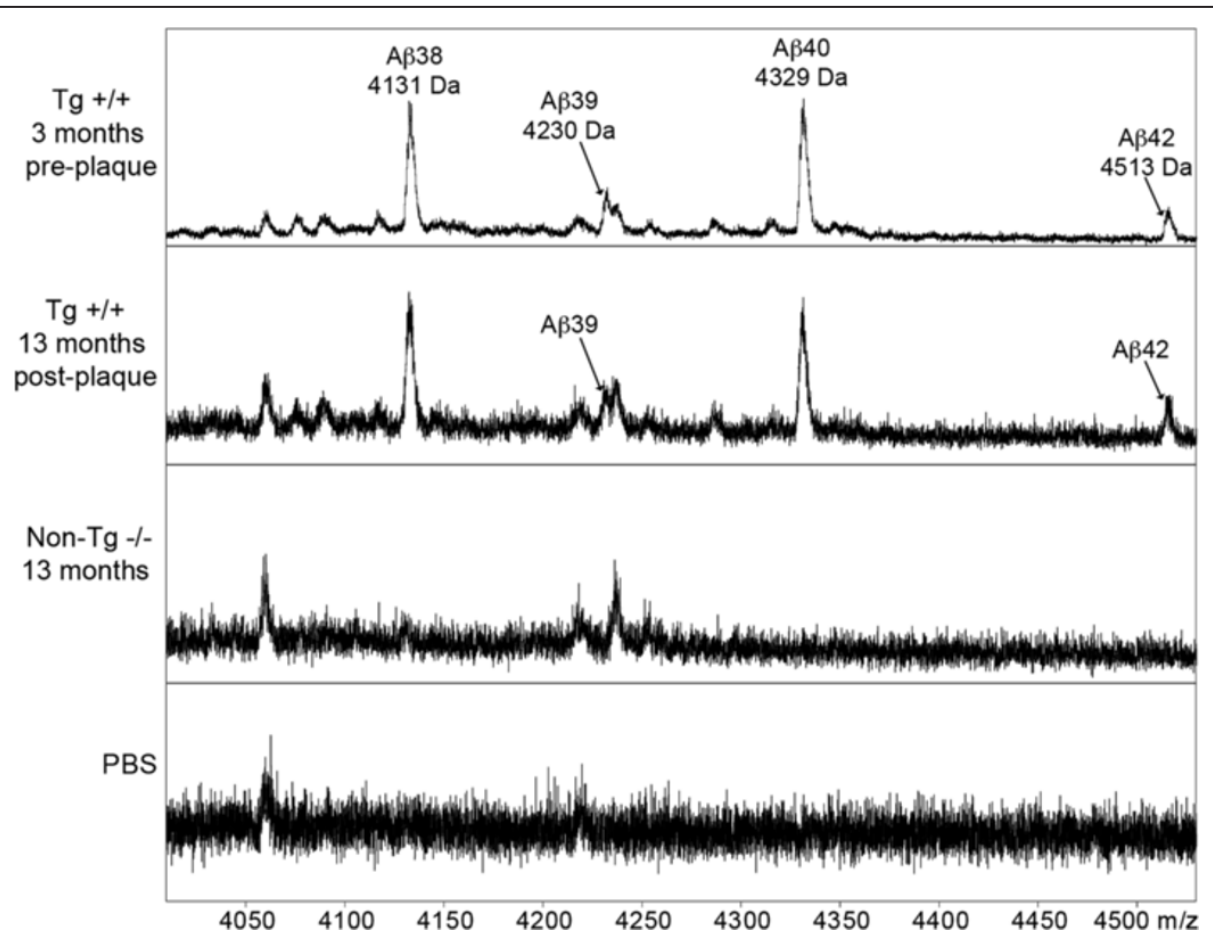

Figure 5 MALDI-MS spectra of immunoprecipitated $A \beta$ peptides from rat CSF. A $\beta$ peptides were immunoprecipitated from rat CSF with the W0-2 antibody and further subjected to MALDI-MS analysis. Peaks correspond to signals for $A \beta_{38,} A \beta_{39}, A \beta_{40}$ and $A \beta_{42}$ with theoretical monoisotopic masses of $4130.0 \mathrm{Da}, 4229.0 \mathrm{Da}$, 4328.2 Da and 4512.3 Da respectively. Note that the differences in measured versus theoretical masses are predominantly due to the linear detection method used. Signals observed in the non-transgenic animals and the PBS control result from either protein-G sepharose, the antibody or other non-specific binding components of the CSF. 

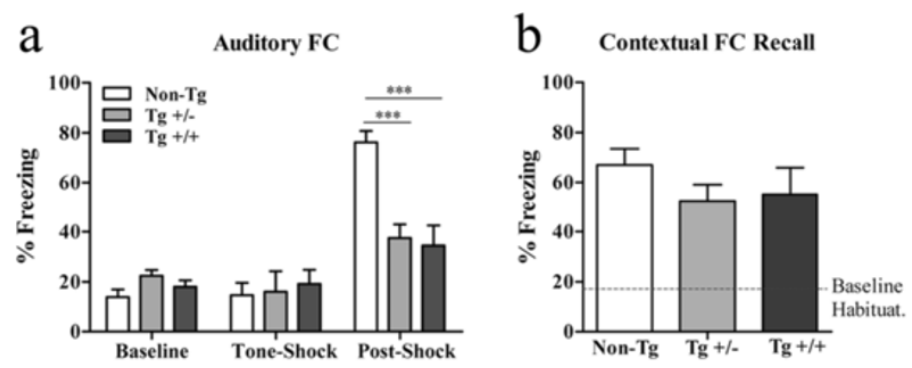

d

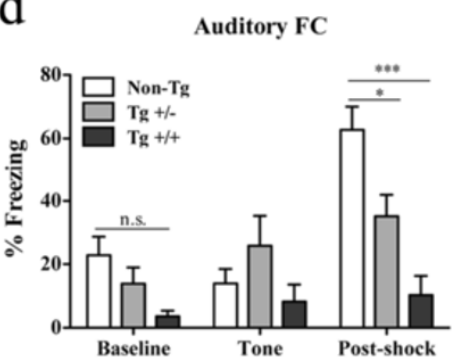

e

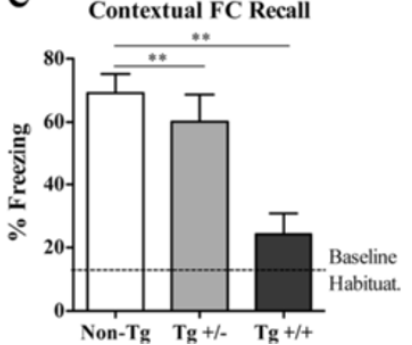

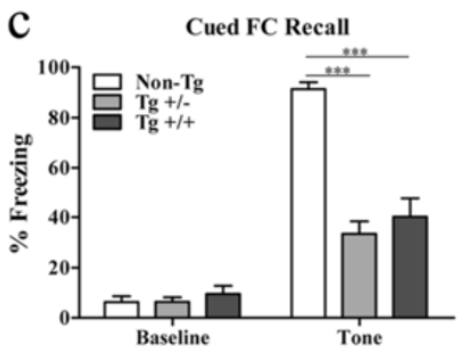

3 months

Pre-plaque

f

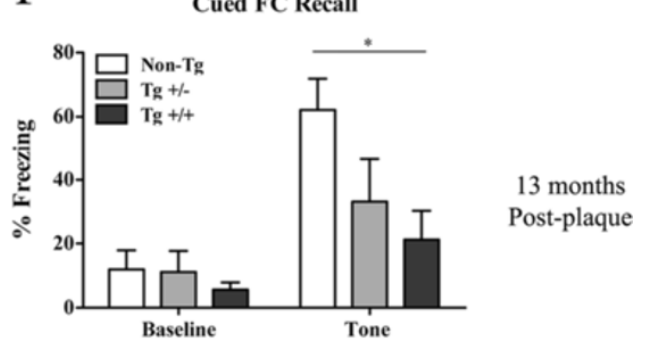

Figure 6 Impaired auditory fear conditioning in McGill-Thy1-APP transgenic rats. Freezing responses in a-c) 3 month-old and d-f) 13 month-old transgenic rats. Following two days of habituation and animal handling, auditory fear conditioning was tested (a, d) followed by assessment of contextual fear conditioning $24 \mathrm{~h}$ later (b, e). The following day (48 hs after auditory conditioning), cued fear responses were examined in a different arena (c, f). Note the progression of auditory and contextual fear conditioning deficits as the amyloid pathology advanced from pre- to post-plaque stages. $\mathbf{a}, \mathbf{c}, \mathbf{d}, \mathbf{f}$ ) Two-Way ANOVA, followed by Bonferroni post-hoc test. b, e) One-Way ANOVA, followed by Bonferroni post-hoc test. Error bars represent mean $\pm \mathrm{SEM}$. ${ }^{*} P<0.05$, ${ }^{* *} P<0.01,{ }^{* * *} P<0.001$.

heterozygote rats had comparable fear conditioning responses throughout all test phases. However, with increasing age and advancing amyloid pathology, fear conditioning deficits severely progressed in homozygote animals (Figure 6d-f).

We observed marked differences in fear response acquisition between transgenic and non-transgenic rats during the post-shock phase at 13 months (Figure 6d). Both heterozygote and homozygote rats exhibited lower freezing responses compared to non-transgenic animals $\left(\mathrm{F}_{2,19}=13.59 ; \mathrm{p}<0.05\right.$ and $\left.\mathrm{p}<0.001\right)$. Non-transgenic animals presented a significant increase in freezing behavior, with respect to their baseline response $\left(F_{2,14}=25.6\right.$; $\mathrm{p}<0.001)$. There was a mild learning response in heterozygote animals $\left(\mathrm{F}_{2,14}=4.95 ; \mathrm{p}<0.05\right)$ with respect to their baseline freezing behavior. Conversely, transgenic homozygote rats exhibited significant fear conditioning deficits as evidenced by comparable freezing levels throughout all test phases $\left(\mathrm{F}_{2,10}=1.01 ; \mathrm{p}>0.05\right)$. All animals exhibited low, comparable freezing behavior at baseline and during the initial presentation of the tone.

In 13-month old transgenic rats with advanced amyloid pathology we revealed marked contextual fear conditioning deficits in homozygote animals. Non-transgenic and transgenic heterozygote rats exhibited high freezing responses ( $\sim 70 \%$ and $\sim 60 \%$ freezing, respectively) (Figure $6 \mathrm{e})$. Conversely, freezing behavior was significantly lower in McGill homozygote transgenic rats $\left(\mathrm{F}_{2,19}=9.528 ; \mathrm{p}<0.01\right)$. During fear memory retrieval in a different context (Figure 6f), all groups exhibited low, comparable baseline freezing. Upon tone presentation, homozygote rats presented significantly lower freezing responses compared to non-transgenic animals $\left(\mathrm{F}_{2,19}=3.37 ; \mathrm{p}<0.05\right)$.

Importantly, at both time points examined, there were no differences in locomotor activity and/or pain sensitivity between rat groups (Additional file 6: Figure S5), suggesting that the reduced fear conditioning responses (freezing behavior) in transgenic rats were not influenced by any differences in sensitivity to pain or by increased locomotion.

\section{Impaired novel object recognition \& location}

In the novel object recognition test, McGill-R-Thy1-APP rats were able to discriminate the novel object better than chance levels (object recognition index $=0.2$ ), however they exhibited significantly lower object recognition indices compared to wild type animals (Figure 7). An impairment in object recognition memory was detectable at early stages of the amyloid pathology, months prior to extracellular $A \beta$ deposition (Figure 7a) in McGill transgenic rats $\left(\mathrm{F}_{2,19}=10.61 ; \mathrm{p}<0.001\right.$ and $\mathrm{p}<0.05$, respectively $)$. Novel object location (Figure 7b) was also significantly impaired in heterozygote animals at this early stage but, despite the trend, did not appear significantly affected in homozygote rats $\left(\mathrm{F}_{2,19}=3.031 ; \mathrm{p}<0.05\right.$ and $\mathrm{p}>0.05$, respectively). At 13 months of age, McGill transgenic 


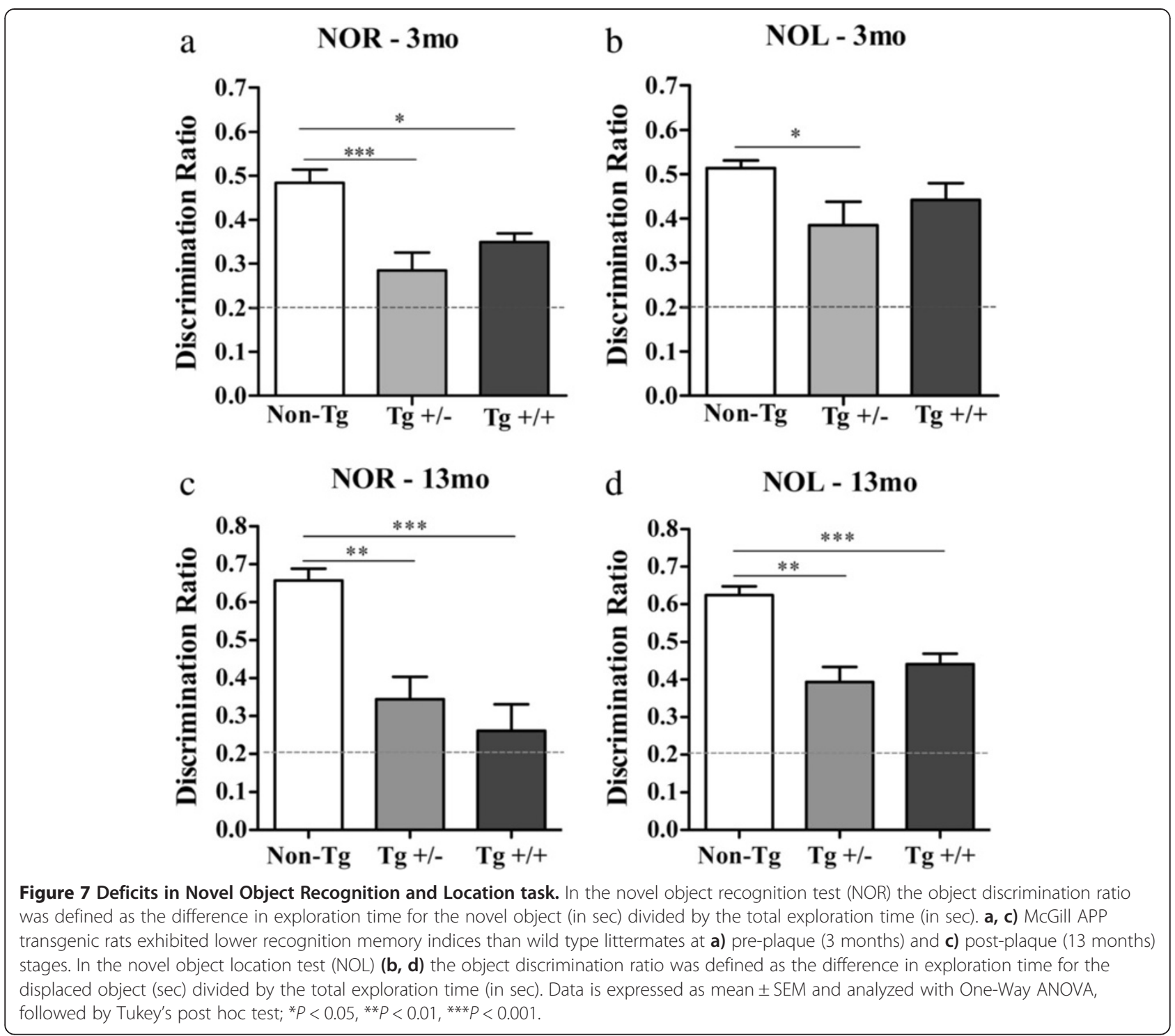

heterozygote and homozygote rats showed significant impairments in object recognition (Figure $7 \mathrm{c}, \mathrm{F}_{2,21}=$ 13.87; $\mathrm{p}<0.001$ ), with recognition indices close to chance levels, as well as deficits in location memory (Figure $7 \mathrm{~d}$, $\left.\mathrm{F}_{2,21}=16.41 ; \mathrm{p}<0.001\right)$, compared to non-transgenic animals.

\section{Discussion}

The concept that $A \beta$ accumulates within neurons remains a matter of controversial debate. However, it is widely accepted that a central event in $\mathrm{AD}$ pathogenesis is the abnormal accumulation of $A \beta$ and its related toxins, either due to increased production or to deficits in clearance mechanisms $[52,53]$. A $\beta$ peptides, initially discovered extracellularly, are the core component of amyloid plaques in AD and DS brains [54,55]. Several studies have reported the existence of intracellular $A \beta$ within cultured neurons [36,56-59] as well as in postmortem brains from AD [14,16,60], DS subjects [17-19] and in transgenic rodent models [10,12,13,61,62].

Despite the above-mentioned studies, a valid concern has been raised regarding some of the antibodies applied for intracellular $A \beta$ immunodetection, which could theoretically also recognize the A $\beta$ sequence as part of APP and in CTFs. This argument was recently put forward in a study by Winton and colleagues who further concluded that the intraneuronal material in the wellestablished 3xTg-AD mouse model is not $\mathrm{A} \beta$ but in fact, solely APP [30]. The idea that only APP accumulates intraneuronally is thought-provoking and additionally, whether the intracellular $A \beta$ pathology causes some of the symptoms in human $\mathrm{AD}$ remains unknown. 
In this report, we have investigated the molecular species that accumulate intraneuronally in McGill-R-Thy1-APP rats and examined in parallel the presence of cognitive impairments, in a model which is closer to the human pathology than transgenic mice. To investigate the intracellular $\mathrm{A} \beta$ pathology, we have performed high-magnification quantitative co-localization/exclusion analysis, using three different monoclonal antibodies specific for $A \beta$ : 1) McSA1, against $A \beta$ residues $1-12$; 2) MOAB-2, against $A \beta$ residues 1-4 and 3) Nu1, a conformation-specific antibody which recognizes A $\beta$ oligomers [40]. These antibodies were coincubated with a polyclonal antibody (pab27576) against the C-terminal domain of full-length APP. The present study revealed a consistent subcellular segregation of immunoreactive sites detected by $A \beta$-specific antibodies and pab27576 within neurons of different brain areas, at preand post-plaque stages of the amyloid pathology. Importantly, our co-localization/exclusion analysis also revealed that the intracellularly accumulated material is likely a heterogeneous mixture of $\mathrm{A} \beta, \mathrm{APP}$ and CTFs.

The examination of the amyloid pathology with super-resolution microscopy permitted us to further reveal a clear separation of the subcellular location of $A \beta-$ immunoreactivity from that of APP/CTFs. Similar compelling evidence supporting the existence of bonafide intraneuronal $A \beta$ peptides has been provided by ELISA analysis on laser microdissected pyramidal neurons from sporadic AD cases [63]. Future studies of this nature are warranted in the McGill-R-Thy1-APP model.

We have observed a certain degree of overlap between $\mathrm{A} \beta$ antibodies and pab27576 by confocal microscopy. This likely reflects the presence of $\mathrm{A} \beta$ and APP/CTFs within the same intracellular location but does not necessarily imply that the antibodies are identifying the same molecules. In the experimental conditions employed for the confocal imaging, the resolution was of $250 \mathrm{~nm}$ in the $x, y$ planes, and $700 \mathrm{~nm}$ in $z$; an area sufficient to accommodate thousands of molecules and even neighboring organelles. Notably, when the McSA1 and pab27576 signals were resolved by SIM, McSA1 immunoreactivity became almost completely dissociated from pab27576 and was found in distinct compartments. It should be kept in mind, however, that this super-resolution technique also has its limitations. Because the mathematical algorithms reconstruct images based on Moiré patterns caused by the structured illumination, the technique is less effective at reassigning signal that is diffuse or weak. It is then possible that we have failed to detect low levels of A $\beta$ or APP at plasma membrane locations.

Previous work on the McGill-R-Thy1-APP transgenic rat has provided additional evidence to support that a considerable component of the intracellular material detected by McSA1 is A $\beta$. Pre-adsorption of this antibody with synthetic $\mathrm{A} \beta_{42}$ completely abolished McSA1 immunoreactivity. Conversely, incubation with the same molar concentration of a cleaved fragment of APP did not result in diminished signal intensity [11], reinforcing the specificity of the McSA1 antibody for $A \beta$ compared to APP-derived peptides [36].

In this study, we further observed that the intraneuronal $A \beta$-specific immunolabel was hardly detectable in close proximity to amyloid deposits. One interpretation could be that the intracellular pool of $A \beta$ may act as a source for the formation of extracellular amyloid deposits [14]. Notably, in DS brains intracellular A $\beta$ immunoreactivity diminishes with increasing age and advanced AD pathology $[18,19]$. Furthermore, in brains from APP transgenic mice conformation-specific antibodies have revealed the early appearance of intraneuronal fibrillar and oligomeric A $\beta$ immunoreactivity, which declined as amyloid plaques appeared, and further became evident in the extracellular space [10]. Alternatively, the apparent decline in intracellular $A \beta$ signal may be the result of the intense reactivity of extracellular $A \beta$, potentially sequestering antibodies and creating steric hindrance, thus lowering the availability of intracellular epitopes.

The biochemical data presented in this report indicates that soluble $A \beta_{40}$ and $A \beta_{42}$ peptides are already abundant during amyloid plaque-free stages. We assert that this material reflects true A $\beta$ (cleaved from APP), as the ELISA approach applied in this study consisted of Cterminus specific anti-A $\beta$ capture antibodies, which do not recognize CTFs or APP molecules. In the McGill transgenic rat, ELISA analysis revealed robust accumulation of soluble $A \beta$ species at 3 and 7 months of age (in cortex and hippocampus), with a preferential progressive and incremental accumulation of $A \beta_{42}$ compared to $\mathrm{A} \beta_{40}$ peptides at advanced ages. Such a situation is similar to that observed in human AD and DS brains $[16,18,64]$. This finding is of great significance considering that cognitive deficits paralleled the early accumulation of soluble $\mathrm{A} \beta$ peptides and further progressed across age and with the advancement of the soluble $\mathrm{A} \beta_{42}$ pathology.

To further address this issue, we analyzed whether there was an association between the average concentrations of $\mathrm{A} \beta$ peptides and the magnitude of behavior deficits, across the temporal progression of the amyloid pathology in transgenic animals. We calculated a cognitive index, adding the scores obtained throughout the different phases of the two behavioral paradigms employed, and expressing them as a $z$ score. This analysis revealed a trend reflecting that higher concentrations of soluble $A \beta_{42}$ peptides correlated with lower indices of cognitive performance (Figure 8a). No such correlation was evident for soluble $\mathrm{A} \beta_{40}$ peptides (Figure $8 \mathrm{~b}$ ) or insoluble $\mathrm{A} \beta_{42}$ (Figure $8 \mathrm{c}$ ). However, there was a significant association between the levels of insoluble $A \beta_{40}$ peptides and cognitive 
decline (Figure 8d). Although this correlation analysis cannot establish causality it is consistent with the concept that soluble forms of $A \beta_{42}$ are highly toxic species.

To determine the occurrence of $A \beta$ peptides in the rat CSF we resorted to $A \beta$ immunoprecipiation followed by MALDI-MS analysis, before and after the formation of amyloid deposits. This technique allowed the detection of C-terminally truncated peptides, including $A \beta_{38}$, $\mathrm{A} \beta_{39}, \mathrm{~A} \beta_{40}$ and $\mathrm{A} \beta_{42}$ species, as early as 3 months of age; a time point which precedes amyloid plaque deposition by several months (4-6 months). The distinct pattern of $A \beta$ peptides observed in rat CSF compared to human CSF (which includes more species, ranging from $1-12$ to $1-42$ ) may reflect differences in the $\gamma$-secretase complex or differential $A \beta$ clearance patterns between human and rodent species. Importantly, this is one of the first reports applying $A \beta$ immunoprecipitation followed by MALDI-MS analysis in CSF from a transgenic AD model, providing a robust, novel platform for the assessment of $A \beta$ expression profiles in biological fluids of transgenic models. Furthermore, the CSF detection of $A \beta$ peptides suggest a dynamic state of these molecules, where some accumulate inside neurons, and some are exported to the extracellular space, from where they can reach the CSF even in the absence of amyloid plaques in the brain parenchyma.

A good number of previous studies support the tenet that the occurrence of intraneuronal $A \beta$ accumulation can have early, deleterious effects in CNS functions $[8,12,61,65]$. In our study, we observed strong $A \beta-$ immunoreactivity in the amygdala at pre-plaque (intraneuronal) and post-plaque stages; changes which likely account for the fear conditioning deficits reported at both time points. Emotional disturbances are a common early symptom in AD patients and such changes may be a reflection of early amygdalar damage [66,67]. The fact that cognitive impairments were seen at the pre-plaque stage, where $A \beta$ could be detected intraneuronally (by IHC) and in CSF (by MALDI-MS), suggests that a combination of intraneuronal and soluble extracellular $A \beta$ may be responsible for impairing neuronal function at early time points. A role for $A \beta$-mediated toxicity is further supported by the fact that cognitive deficits progressed according with the incremental accumulation of the amyloid pathology, in particular, increased levels of soluble $A \beta_{42}$ (Figure 8a). However, we do not discard the possibility that the presence of other intracellular species, such as CTFs may also contribute to neuronal
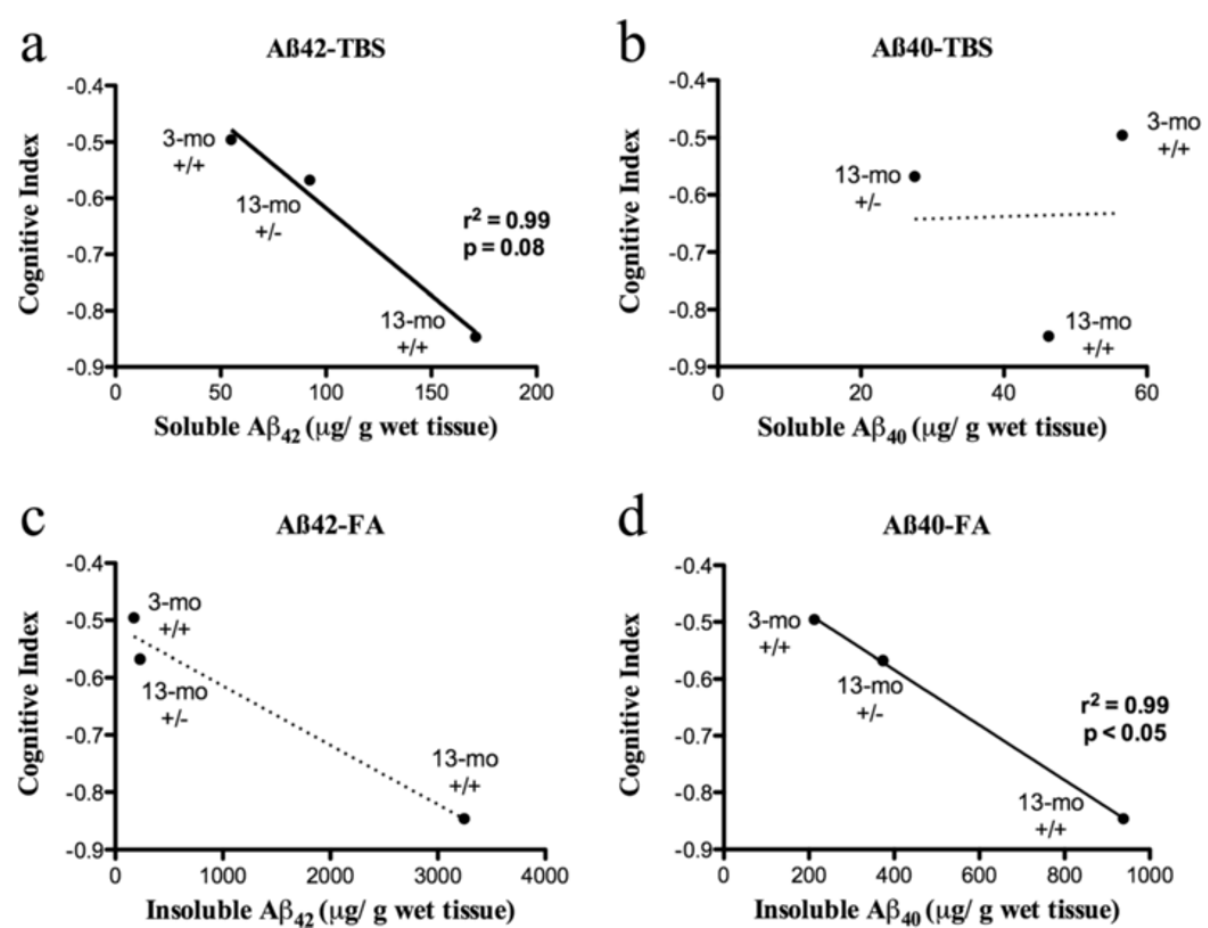

Figure 8 Link between soluble $\mathbf{A} \boldsymbol{\beta}$ pathology and cognitive impairment. Correlation between average levels of soluble (a, $\mathbf{b})$ and insoluble ( $\mathbf{c}, \mathbf{d}) A \beta_{42}$ and $A \beta_{40}$ and the magnitude of cognitive impairments in transgenic animals, during the temporal progression of the AD-like amyloid pathology. A cognitive index was calculated based on the animals' performance throughout all phases of the two behavioral paradigms employed, and expressed as a z score. Average values were analyzed with linear regression. Note the negative correlation between cognition and the levels of soluble $A \beta_{42}$ peptides but not with soluble $A \beta_{40}$. 
dysfunction in McGill transgenic rats. $\beta$-CTF can be toxic to primary rat hippocampal neurons in culture [68], and is capable of inducing impairments in spatial learning and working memory in vivo [69-71].

Finally, we propose that an analogous, intraneuronal $A \beta$ pathology during the pre-diagnostic stages of human $\mathrm{AD}$ should also have a negative impact on cognitive function. However, due to population-based tests and the well-known aspect of neural reserve [72] such early deficits may be difficult to reveal in the human species. We therefore suggest that self-to-self assessments that reflect a cognitive decline from an individual-adjusted baseline may be required to detect early (and yet subtle) memory deficits in pre-symptomatic human AD.

\section{Conclusions}

This study demonstrates that a considerable component of the intracellular AD-like pathology in McGill-Thy1APP rats consists of $A \beta$ peptides. The intracellular material reflects a variety of molecular species, including free $A \beta, A P P, C T F$ s as well as aggregated $A \beta$ peptides in the form of oligomers. Future investigations on this issue are warranted, particularly to examine which form of $A \beta$ predominates within neurons and in which compartment; as well as dissecting the differential contributions of intraneuronal species to the development and progression of CNS dysfunction. A similar pathological situation is likely to occur at the earliest, silent stages of AD progression in the human brain.

\section{Additional files}

Additional file 1: Video. Following image reconstruction and registration, serial $z$ planes were assembled to form a 3D model using the Volocity 3D Image Analysis Software. The video shows different rotations and magnifications of the 3D model revealing a clear dissociation between intraneuronal McSA1 (green) and pab27576 (red) immunoreactivities.

Additional file 2: Figure S1. Double immunolabeling with McSA1 and pab27576 antibodies. Representative high-magnification confocal micrographs depicting lack of complete co-localization between pab27576 (red) and McSA1 (green) immunoreactive sites at 3 months and 13 months in CA1 neurons of the hippocampus, and neurons of lamina $V$ and III of the parietal cortex. Note the lack of complete overlap between the intracellular A $\beta$ - and APP/CTF-specific immunoreactive signals at both time points. Scale bar $=10 \mu \mathrm{m}$.

Additional file 3: Figure S2. Double immunolabeling with MOAB-2, McSA1 and pab27576. a-b) Representative high-magnification confocal micrographs depicting co-localization between pab27576 (red) and MOAB-2 (green) in CA1 neurons of the hippocampus a) and neurons of lamina $\mathrm{V}$ of the parietal cortex b) at post-plaque stages (13 months). c) Co-localization between McSA1 (green) and pab27576 (red) immunoreactive sites in neurons of the cerebral cortex (lamina V) at 13 months. Note the absence of pab27576 immunoreactivity in amyloid plaques (a-c). Scale bar $=10 \mu \mathrm{m}$

Additional file 4: Figure S3. Double immunolabeling with Nu1 and pab27576. Representative high-magnification confocal micrographs depicting lack of complete co-localization between pab27576 (APP) CTF-specific sites, red) and Nu1 (A $\beta$ oligomer-specific sites, green).
These images illustrate CA1 neurons of the hippocampus and neurons of lamina $V$ and III of the parietal cortex from animals aged 3 and 13 months. Scale bar $=10 \mu \mathrm{m}$.

Additional file 5: Figure S4. Quantification of $A \beta_{40}$ and $A \beta_{42}$ levels by ELISA in cerebellum. $A \beta_{40}$ and $A \beta_{42}$ levels in cerebellum homogenates from non-transgenic ( $-/-)$, heterozygous (+/-) and homozygous transgenic $(+/+)$ rats at different ages (3 months, 7 months and 13-15 months) were quantified with specific G2-10/W0-2 and G2-13/W0-2 sandwich ELISAs, respectively. Values were normalized to total protein concentration and expressed as means \pm SEM. One-way ANOVA, followed by Dunnett's post-hoc test.

Additional file 6: Figure S5. Analysis of locomotor activity and pain sensitivity in McGill transgenic rats. a, c) Freezing responses recorded during a $5 \mathrm{~min}$ exploratory session in the testing environment. The animals were allowed to explore the arena and returned to their home cages. No stimuli were presented. b, d) Analysis of tactile sensitivity in the rat hind paw using Von Frey filaments of increasing force. The graph depicts the average withdrawal thresholds to mechanical stimulation, expressed in grams of pressure. Data is expressed as mean $\pm \mathrm{SEM}$. One-Way ANOVA, followed by Bonferroni post-hoc tests.

\section{Abbreviations}

AD: Alzheimer's disease; A $\beta$ : Amyloid- $\beta$; APP: Amyloid precursor protein; CSF: Cerebro-spinal fluid; CTF: C-terminal fragment; DS: Down syndrome; FA: Formic acid; IHC: Immunohistochemistry; MALDI: Matrix assisted laser desorption ionization; MS: Mass spectrometry; NGS: Normal goat serum; NOL and NOR: Novel object location and recognition; PBS: Phosphate-buffered saline; sAPP-a: soluble APP-alpha; SIM: Structured illumination microscopy; TBS: Tris-buffered saline.

\section{Competing interests}

WLK is co-founder of Acumen Pharmaceuticals, an Alzheimer's biotech licensed by Northwestern University to develop antibodies against toxic Amyloid- $\beta$ oligomers for Alzheimer's therapeutics. All other authors have nothing to disclose.

\section{Authors' contributions}

MFI, SA, LR, LMM, GM and ACC designed the research. MFI, SA, LR, LMM, AD, CW, SDC performed the research. WLK contributed to the immunological characterization of the Nu1 antibody. MFI, SA, LR, LMM, CW, SDC, WLK, GM and ACC wrote the manuscript. ACC coordinated the project. All authors read and approved the final manuscript.

\section{Acknowledgements}

This research was supported by a Canadian Institute for Health and Research grant (MOP-97776) to ACC, by McGill start-up funds to GM and LMM, and by the Deutsche Forschungsgemeinschaft (DFG) through MU901, the Sonderforschungsbereich SFB740, the German Federal Ministry of Education and Research through the Kompetenznetz Degenerative Demenzen (Förderkennzeichen 01 Gl 0723) to GM. GM is holding a CRC Tier 1 linked to CFI infrastructure support. LMM is also funded by a Young Investigator Award from the Alzheimer Society of Canada (2013-2016). WLK was supported by a Zenith Award from the Alzheimer's Association. MFI is the recipient of a Biomedical Doctoral Award from the Alzheimer Society of Canada. LR is supported by the Richard and Edith Strauss Postdoctoral Fellowship in Medicine from the Richard and Edith Strauss Canada Foundation. SDC is the holder of the Charles E. Frosst-Merck Post-Doctoral Fellowship. ACC is the holder of the McGill University Charles E. Frosst/Merck Chair in Pharmacology. We would like to thank Dr. Elke Küster-Schöck and the Cell Imaging and Analysis Network Center at the McGill Biology Department for their help with super-resolution microscopy. The Cuello Lab wishes to thank Dr A. Frosst, the Frosst family and Merck Canada for their unrestricted support.

\section{Author details}

${ }^{1}$ Department of Pharmacology and Therapeutics, McGill University, 3655 Sir-William-Osler Promenade, Room 1210, Montreal, Quebec, Canada. ${ }^{2}$ Department of Anatomy and Cell Biology, McGill University, Montreal, Canada. ${ }^{3}$ Department of Neurology and Neurosurgery, McGill University, Montreal, Canada. ${ }^{4}$ Intitutes of Chemistry and Biochemistry, Freie Universität, 
Berlin, Germany. ${ }^{5}$ Cognitive Neurology and Alzheimer's Disease Center, Northwestern University Institute for Neuroscience, Chicago, USA.

\section{Received: 16 April 2014 Accepted: 7 May 2014}

Published: 5 June 2014

\section{References}

1. Prince M, Prina M, Guerchet M (2013) World Alzheimer Report 2013. Journey of Caring. An analysis of long-term care for dementia. Alzheimer's Disease International, London, pp 1-33

2. Jack CR Jr, Knopman DS, Jagust WJ, Petersen RC, Weiner MW, Aisen PS, Shaw LM, Vemuri P, Wiste HJ, Weigand SD, Lesnick TG, Pankratz VS, Donohue MC, Trojanowski JQ (2013) Tracking pathophysiological processes in Alzheimer's disease: an updated hypothetical model of dynamic biomarkers. Lancet Neurol 12:207-216

3. Villemagne VL, Burnham S, Bourgeat P, Brown B, Ellis KA, Salvado O, Szoeke C, Macaulay SL, Martins R, Maruff P, Ames D, Rowe CC, Masters CL, Australian Imaging B, Lifestyle Research G (2013) Amyloid beta deposition, neurodegeneration, and cognitive decline in sporadic Alzheimer's disease: a prospective cohort study. Lancet Neurol 12:357-367

4. Bateman RJ, Xiong C, Benzinger TL, Fagan AM, Goate A, Fox NC, Marcus DS, Cairns NJ, Xie X, Blazey TM, Holtzman DM, Santacruz A, Buckles V, Oliver A, Moulder K, Aisen PS, Ghetti B, Klunk WE, McDade E, Martins RN, Masters CL, Mayeux R, Ringman JM, Rossor MN, Schofield PR, Sperling RA, Salloway S, Morris JC, Dominantly Inherited Alzheimer N (2012) Clinical and biomarker changes in dominantly inherited Alzheimer's disease. N Engl J Med 367:795-804

5. Karran E, Mercken M, De Strooper B (2011) The amyloid cascade hypothesis for Alzheimer's disease: an appraisal for the development of therapeutics. Nat Rev Drug Discov 10:698-712

6. Hardy JA, Higgins GA (1992) Alzheimer's disease: the amyloid cascade hypothesis. Science 256:184-185

7. Sperling RA, Aisen PS, Beckett LA, Bennett DA, Craft S, Fagan AM, Iwatsubo T, Jack CR Jr, Kaye J, Montine TJ, Park DC, Reiman EM, Rowe CC, Siemers E, Stern Y, Yaffe K, Carrillo MC, Thies B, Morrison-Bogorad M, Wagster MV, Phelps CH (2011) Toward defining the preclinical stages of Alzheimer's disease: recommendations from the National Institute on Aging-Alzheimer's Association workgroups on diagnostic guidelines for Alzheimer's disease. Alzheimers Dement 7:280-292

8. Wirths O, Multhaup G, Czech C, Feldmann N, Blanchard V, Tremp G, Beyreuther K, Pradier L, Bayer TA (2002) Intraneuronal APP/A beta trafficking and plaque formation in beta-amyloid precursor protein and presenilin-1 transgenic mice. Brain Pathol 12:275-286

9. Ferretti MT, Partridge V, Leon WC, Canneva F, Allard S, Arvanitis DN, Vercauteren F, Houle D, Ducatenzeiler A, Klein WL, Glabe CG, Szyf M, Cuello AC (2011) Transgenic mice as a model of pre-clinical Alzheimer's disease. Curr Alzheimer Res 8:4-23

10. Leon WC, Canneva F, Partridge V, Allard S, Ferretti MT, DeWilde A, Vercauteren F, Atifeh R, Ducatenzeiler A, Klein W, Szyf M, Alhonen L, Cuello AC (2010) A novel transgenic rat model with a full Alzheimer's-like amyloid pathology displays pre-plaque intracellular amyloid-beta-associated cognitive impairment. J Alzheimers Dis 20:113-126

11. Billings LM, Oddo S, Green KN, McGaugh JL, LaFerla FM (2005) Intraneuronal Abeta causes the onset of early Alzheimer's disease-related cognitive deficits in transgenic mice. Neuron 45:675-688

12. Oddo S, Caccamo A, Shepherd JD, Murphy MP, Golde TE, Kayed R, Metherate R, Mattson MP, Akbari Y, LaFerla FM (2003) Triple-transgenic model of Alzheimer's disease with plaques and tangles: intracellular Abeta and synaptic dysfunction. Neuron 39:409-421

13. Casas C, Sergeant N, Itier JM, Blanchard V, Wirths O, van der Kolk N, Vingtdeux V, van de Steeg E, Ret G, Canton T, Drobecq H, Clark A, Bonici B, Delacourte A, Benavides J, Schmitz C, Tremp G, Bayer TA, Benoit P, Pradier L (2004) Massive CA1/2 neuronal loss with intraneuronal and N-terminal truncated Abeta42 accumulation in a novel Alzheimer transgenic model. Am J Pathol 165:1289-1300

14. Gyure KA, Durham R, Stewart WF, Smialek JE, Troncoso JC (2001) Intraneuronal abeta-amyloid precedes development of amyloid plaques in Down syndrome. Arch Pathol Lab Med 125:489-492

15. Lemere CA, Blusztajn JK, Yamaguchi H, Wisniewski T, Saido TC, Selkoe DJ (1996) Sequence of deposition of heterogeneous amyloid beta-peptides and APO E in Down syndrome: implications for initial events in amyloid plaque formation. Neurobiol Dis 3:16-32
16. Mori C, Spooner ET, Wisniewsk KE, Wisniewski TM, Yamaguch H, Saido TC, Tolan DR, Selkoe DJ, Lemere CA (2002) Intraneuronal Abeta42 accumulation in Down syndrome brain. Amyloid 9:88-102

17. Gouras GK, Tsai J, Naslund J, Vincent B, Edgar M, Checler F, Greenfield JP, Haroutunian V, Buxbaum JD, Xu H, Greengard P, Relkin NR (2000) Intraneuronal Abeta42 accumulation in human brain. Am J Pathol 156:15-20

18. Takahashi RH, Milner TA, Li F, Nam EE, Edgar MA, Yamaguchi H, Beal MF, Xu H, Greengard P, Gouras GK (2002) Intraneuronal Alzheimer abeta42 accumulates in multivesicular bodies and is associated with synaptic pathology. Am J Pathol 161:1869-1879

19. D'Andrea MR, Nagele RG, Wang HY, Peterson PA, Lee DH (2001) Evidence that neurones accumulating amyloid can undergo lysis to form amyloid plaques in Alzheimer's disease. Histopathology 38:120-134

20. Fernandez-Vizarra P, Fernandez AP, Castro-Blanco S, Serrano J, Bentura ML, Martinez-Murillo R, Martinez A, Rodrigo J (2004) Intra- and extracellular Abeta and PHF in clinically evaluated cases of Alzheimer's disease. Histol Histopathol 19:823-844

21. Walsh DM, Tseng BP, Rydel RE, Podlisny MB, Selkoe DJ (2000) The oligomerization of amyloid beta-protein begins intracellularly in cells derived from human brain. Biochemistry 39:10831-10839

22. Takahashi RH, Almeida CG, Kearney PF, Yu F, Lin MT, Milner TA, Gouras GK (2004) Oligomerization of Alzheimer's beta-amyloid within processes and synapses of cultured neurons and brain. J Neurosci 24:3592-3599

23. Jin M, Shepardson N, Yang T, Chen G, Walsh D, Selkoe DJ (2011) Soluble amyloid beta-protein dimers isolated from Alzheimer cortex directly induce Tau hyperphosphorylation and neuritic degeneration. Proc Natl Acad Sci U S A 108:5819-5824

24. Walsh DM, Klyubin I, Fadeeva JV, Cullen WK, Anwyl R, Wolfe MS, Rowan MJ, Selkoe DJ (2002) Naturally secreted oligomers of amyloid beta protein potently inhibit hippocampal long-term potentiation in vivo. Nature 416:535-539

25. Shankar GM, Li S, Mehta TH, Garcia-Munoz A, Shepardson NE, Smith I, Brett FM, Farrell MA, Rowan MJ, Lemere CA, Regan CM, Walsh DM, Sabatini BL, Selkoe DJ (2008) Amyloid-beta protein dimers isolated directly from Alzheimer's brains impair synaptic plasticity and memory. Nat Med 14:837-842

26. Lambert MP, Barlow AK, Chromy BA, Edwards C, Freed R, Liosatos M, Morgan TE, Rozovsky I, Trommer B, Viola KL, Wals P, Zhang C, Finch CE, Krafft GA, Klein WL (1998) Diffusible, nonfibrillar ligands derived from Abeta1-42 are potent central nervous system neurotoxins. Proc Natl Acad Sci U S A 95:6448-6453

27. Cleary JP, Walsh DM, Hofmeister JJ, Shankar GM, Kuskowski MA, Selkoe DJ, Ashe KH (2005) Natural oligomers of the amyloid-beta protein specifically disrupt cognitive function. Nat Neurosci 8:79-84

28. Lesne S, Koh MT, Kotilinek L, Kayed R, Glabe CG, Yang A, Gallagher M, Ashe $\mathrm{KH}$ (2006) A specific amyloid-beta protein assembly in the brain impairs memory. Nature 440:352-357

29. Bruno MA, Leon WC, Fragoso G, Mushynski WE, Almazan G, Cuello AC (2009) Amyloid beta-induced nerve growth factor dysmetabolism in Alzheimer disease. J Neuropathol Exp Neurol 68:857-869

30. Winton MJ, Lee EB, Sun E, Wong MM, Leight S, Zhang B, Trojanowski JQ, Lee VM (2011) Intraneuronal APP, not free Abeta peptides in 3xTg-AD mice: implications for tau versus Abeta-mediated Alzheimer neurodegeneration. J Neurosci 31:7691-7699

31. Cuello AC, Allard S, Ferretti MT (2012) Evidence for the accumulation of Abeta immunoreactive material in the human brain and in transgenic animal models. Life Sci 91:1141-1147

32. Do Carmo S, Cuello AC (2013) Modeling Alzheimer's disease in transgenic rats. Mol Neurodegener 8:37

33. Pegg CC, He C, Stroink AR, Kattner KA, Wang CX (2010) Technique for collection of cerebrospinal fluid from the cisterna magna in rat. J Neurosci Methods 187:8-12

34. Hu L, Wong TP, Cote SL, Bell KF, Cuello AC (2003) The impact of Abeta-plaques on cortical cholinergic and non-cholinergic presynaptic boutons in alzheimer's disease-like transgenic mice. Neuroscience 121:421-432

35. Côté SL, Cuello AC, Ribeiro-da-Silva A (1994) Current protocols for light microscopy immunocytochemistry. In: Cuello AC (ed) Immunohistochemistry II. Wiley, West Sussex, pp 147-168

36. Grant SM, Ducatenzeiler A, Szyf M, Cuello AC (2000) Abeta immunoreactive material is present in several intracellular compartments in transfected, 
neuronally differentiated, P19 cells expressing the human amyloid beta-protein precursor. J Alzheimers Dis 2:207-222

37. Semenenko FM, Bramwell S, Sidebottom E, Cuello AC (1985) Development of a mouse antiperoxidase secreting hybridoma for use in the production of a mouse PAP complex for immunocytochemistry and as a parent cell line in the development of hybrid hybridomas. Histochemistry 83:405-408

38. Allard S, Leon WC, Pakavathkumar P, Bruno MA, Ribeiro-da-Silva A, Cuello AC (2012) Impact of the NGF maturation and degradation pathway on the cortical cholinergic system phenotype. J Neurosci 32:2002-2012

39. Youmans KL, Tai LM, Kanekiyo T, Stine WB Jr, Michon SC, Nwabuisi-Heath E, Manelli AM, Fu Y, Riordan S, Eimer WA, Binder L, Bu G, Yu C, Hartley DM, LaDu MJ (2012) Intraneuronal Abeta detection in 5XFAD mice by a new Abeta-specific antibody. Mol Neurodegener 7:8

40. Lambert MP, Velasco PT, Chang L, Viola KL, Fernandez S, Lacor PN, Khuon D, Gong Y, Bigio EH, Shaw P, De Felice FG, Krafft GA, Klein WL (2007) Monoclonal antibodies that target pathological assemblies of Abeta. J Neurochem 100:23-35

41. Kaden D, Harmeier A, Weise C, Munter LM, Althoff $V$, Rost BR, Hildebrand PW, Schmitz D, Schaefer M, Lurz R, Skodda S, Yamamoto R, Arlt S, Finckh U, Multhaup G (2012) Novel APP/Abeta mutation K16N produces highly toxic heteromeric Abeta oligomers. EMBO Mol Med 4:647-659

42. Ferretti MT, Allard S, Partridge V, Ducatenzeiler A, Cuello AC (2012) Minocycline corrects early, pre-plaque neuroinflammation and inhibits BACE-1 in a transgenic model of Alzheimer's disease-like amyloid pathology. J Neuroinflammation 9:62

43. Bolte S, Cordelieres FP (2006) A guided tour into subcellular colocalization analysis in light microscopy. J Microsc 224:213-232

44. Gustafsson MG, Shao L, Carlton PM, Wang CJ, Golubovskaya IN, Cande WZ, Agard DA, Sedat JW (2008) Three-dimensional resolution doubling in wide-field fluorescence microscopy by structured illumination. Biophys J 94:4957-4970

45. Nader K, Schafe GE, Le Doux JE (2000) Fear memories require protein synthesis in the amygdala for reconsolidation after retrieval. Nature 406:722-726

46. Chaplan SR, Bach FW, Pogrel JW, Chung JM, Yaksh TL (1994) Quantitative assessment of tactile allodynia in the rat paw. J Neurosci Methods 53:55-63

47. Munter LM, Voigt P, Harmeier A, Kaden D, Gottschalk KE, Weise C, Pipkorn R, Schaefer M, Langosch D, Multhaup G (2007) GxxxG motifs within the amyloid precursor protein transmembrane sequence are critical for the etiology of Abeta42. EMBO J 26:1702-1712

48. Munter LM, Botev A, Richter L, Hildebrand PW, Althoff $\mathrm{V}$, Weise C, Kaden D, Multhaup G (2010) Aberrant amyloid precursor protein (APP) processing in hereditary forms of Alzheimer disease caused by APP familial Alzheimer disease mutations can be rescued by mutations in the APP GXxxG motif. J Biol Chem 285:21636-21643

49. Mann DM, Jones D, Prinja D, Purkiss MS (1990) The prevalence of amyloid (A4) protein deposits within the cerebral and cerebellar cortex in Down's syndrome and Alzheimer's disease. Acta Neuropathol 80:318-327

50. Portelius E, Westman-Brinkmalm A, Zetterberg H, Blennow K (2006) Determination of beta-amyloid peptide signatures in cerebrospinal fluid using immunoprecipitation-mass spectrometry. J Proteome Res 5:1010-1016

51. De Strooper B, Simons M, Multhaup G, Van Leuven F, Beyreuther K, Dotti CG (1995) Production of intracellular amyloid-containing fragments in hippocampal neurons expressing human amyloid precursor protein and protection against amyloidogenesis by subtle amino acid substitutions in the rodent sequence. EMBO J 14:4932-4938

52. Hardy J, Selkoe DJ (2002) The amyloid hypothesis of Alzheimer's disease: progress and problems on the road to therapeutics. Science 297:353-356

53. Zlokovic BV, Yamada S, Holtzman D, Ghiso J, Frangione B (2000) Clearance of amyloid beta-peptide from brain: transport or metabolism? Nat Med 6:718-719

54. Glenner GG, Wong CW (1984) Alzheimer's disease: initial report of the purification and characterization of a novel cerebrovascular amyloid protein. Biochem Biophys Res Commun 120:885-890

55. Masters $\mathrm{CL}$, Simms G, Weinman NA, Multhaup G, McDonald BL, Beyreuther K (1985) Amyloid plaque core protein in Alzheimer disease and Down syndrome. Proc Natl Acad Sci U S A 82:4245-4249

56. Grant SM, Shankar SL, Chalmers-Redman RM, Tatton WG, Szyf M, Cuello AC (1999) Mitochondrial abnormalities in neuroectodermal cells stably expressing human amyloid precursor protein (hAPP751). Neuroreport 10:41-46
57. Hartmann T, Bieger SC, Bruhl B, Tienari PJ, Ida N, Allsop D, Roberts GW, Masters CL, Dotti CG, Unsicker K, Beyreuther K (1997) Distinct sites of intracellular production for Alzheimer's disease A beta40/42 amyloid peptides. Nat Med 3:1016-1020

58. Wertkin AM, Turner RS, Pleasure SJ, Golde TE, Younkin SG, Trojanowski JQ, Lee VM (1993) Human neurons derived from a teratocarcinoma cell line express solely the 695-amino acid amyloid precursor protein and produce intracellular beta-amyloid or A4 peptides. Proc Natl Acad Sci U S A 90:9513-9517

59. Turner RS, Suzuki N, Chyung AS, Younkin SG, Lee VM (1996) Amyloids beta40 and beta42 are generated intracellularly in cultured human neurons and their secretion increases with maturation. J Biol Chem 271:8966-8970

60. Mochizuki A, Tamaoka A, Shimohata A, Komatsuzaki Y, Shoji S (2000) Abeta42-positive non-pyramidal neurons around amyloid plaques in Alzheimer's disease. Lancet 355:42-43

61. Philipson O, Lannfelt L, Nilsson LN (2009) Genetic and pharmacologica evidence of intraneuronal Abeta accumulation in APP transgenic mice. FEBS Lett 583:3021-3026

62. Echeverria V, Ducatenzeiler A, Dowd E, Janne J, Grant SM, Szyf M, Wandosell F, Avila J, Grimm H, Dunnett SB, Hartmann T, Alhonen L, Cuello AC (2004) Altered mitogen-activated protein kinase signaling, tau hyperphosphorylation and mild spatial learning dysfunction in transgenic rats expressing the beta-amyloid peptide intracellularly in hippocampal and cortical neurons. Neuroscience 129:583-592

63. Hashimoto M, Bogdanovic N, Volkmann I, Aoki M, Winblad B, Tjernberg LO (2010) Analysis of microdissected human neurons by a sensitive ELISA reveals a correlation between elevated intracellular concentrations of Abeta42 and Alzheimer's disease neuropathology. Acta Neuropathol 119:543-554

64. Iwatsubo T, Mann DM, Odaka A, Suzuki N, Ihara Y (1995) Amyloid beta protein (A beta) deposition: A beta 42(43) precedes A beta 40 in Down syndrome. Ann Neurol 37:294-299

65. Ferretti MT, Bruno MA, Ducatenzeiler A, Klein WL, Cuello AC (2012) Intracellular Abeta-oligomers and early inflammation in a model of Alzheimer's disease. Neurobiol Aging 33:1329-1342

66. Heun R, Mazanek M, Atzor KR, Tintera J, Gawehn J, Burkart M, Gansicke M, Falkai P, Stoeter P (1997) Amygdala-hippocampal atrophy and memory performance in dementia of Alzheimer type. Dement Geriatr Cogn Disord 8:329-336

67. Mizuno K, Wakai M, Takeda A, Sobue G (2000) Medial temporal atrophy and memory impairment in early stage of Alzheimer's disease: an MRI volumetric and memory assessment study. J Neurol Sci 173:18-24

68. Yankner BA, Dawes LR, Fisher S, Villa-Komaroff L, Oster-Granite ML, Neve RL (1989) Neurotoxicity of a fragment of the amyloid precursor associated with Alzheimer's disease. Science 245:417-420

69. Mitani Y, Yarimizu J, Saita K, Uchino H, Akashiba H, Shitaka Y, Ni K, Matsuoka N (2012) Differential effects between gamma-secretase inhibitors and modulators on cognitive function in amyloid precursor protein-transgenic and nontransgenic mice. J Neurosci: J Soc Neurosci 32:2037-2050

70. Jinno S, Araki K, Matsumoto Y, Suh YH, Yamamoto T (2009) Selective apoptosis induction in the hippocampal mossy fiber pathway by exposure to CT105, the C-terminal fragment of Alzheimer's amyloid precursor protein. Brain Res 1249:68-78

71. Nalbantoglu J, Tirado-Santiago G, Lahsaini A, Poirier J, Goncalves O, Verge G, Momoli F, Welner SA, Massicotte G, Julien JP, Shapiro ML (1997) Impaired learning and LTP in mice expressing the carboxy terminus of the Alzheimer amyloid precursor protein. Nature 387:500-505

72. Scarmeas N, Stern Y (2003) Cognitive reserve and lifestyle. J Clin Exp Neuropsychol 25:625-633

doi:10.1186/2051-5960-2-61

Cite this article as: Iulita et al:: Intracellular A $\beta$ pathology and early cognitive impairments in a transgenic rat overexpressing human amyloid precursor protein: a multidimensional study. Acta Neuropathologica Communications 2014 2:61. 